\title{
A machine learning approach to address air quality changes during the COVID-19 lockdown in Buenos Aires, Argentina
}

\author{
Melisa Diaz Resquin ${ }^{1,2,3, *}$, Pablo Lichtig ${ }^{1,4}$, Diego Alessandrello ${ }^{1}$, Marcelo De Oto ${ }^{1}$, Darío Gómez ${ }^{1,2}$, \\ Cristina Rössler ${ }^{1,5}$, Paula Castesana ${ }^{1,4}$, and Laura Dawidowski ${ }^{1,5, *}$ \\ ${ }^{1}$ Comisión Nacional de Energía Atómica, Gerencia Química, Buenos Aires, Argentina. \\ ${ }^{2}$ Facultad de Ingeniería, Universidad de Buenos Aires, Buenos Aires, Argentina. \\ ${ }^{3}$ Center for Climate and Resilience Research $(\mathrm{CR})^{2}$, Santiago, Chile. \\ ${ }^{4}$ Consejo Nacional de Investigaciones Científicas y Técnicas, Buenos Aires, Argentina. \\ ${ }^{5}$ Instituto de Investigación e Ingeniería Ambiental, Universidad Nacional de San Martín, Buenos Aires, Argentina. \\ ${ }^{*}$ These authors contributed equally to this work.
}

Correspondence: Melisa Diaz Resquin (mdiazresquin@fi.uba.ar), Laura Dawidowski (dawidows@cnea.gov.ar)

\begin{abstract}
.
The COVID-19 (COronaVIrus Disease 2019) pandemic provided the unique opportunity to evaluate the role of a sudden and deep decline in air pollutant emissions in the ambient air of numerous cities worldwide. Argentina, in general, and the Metropolitan Area of Buenos Aires (MABA), in particular, were under strict control measures from March to May 2020. Private vehicle restrictions were intense, and primary pollutant concentrations decreased substantially. To quantify the changes in $\mathrm{CO}$, $\mathrm{NO}, \mathrm{NO}_{2}, \mathrm{PM}_{10}, \mathrm{SO}_{2}$ and $\mathrm{O}_{3}$ concentrations under the stay-at-home orders imposed against COVID-19, we compared the observations during the different lockdown phases with both observations during the same period in 2019 and concentrations that would have occurred under a business-as-usual (BAU) scenario under no restrictions. We employed a Random Forest (RF) algorithm to estimate the BAU concentration levels. This approach exhibited a high predictive performance based on only a handful of available indicators (meteorological variables, air quality concentrations and emission temporal variations) at a low computational cost. Results during testing showed that the model captured the observed daily variations and the diurnal cycles of these pollutants with a normalized mean bias $(N M B)$ of less than $11 \%$ and Pearson correlation coefficients of the diurnal variations of between 0.65 and 0.89 for all the pollutants considered. Based on the Random Forest results, we estimated that the lockdown implied concentration decreases of up to $47 \%(\mathrm{CO}), 60 \%\left(\mathrm{NO}_{\mathrm{x}}\right)$ and $36 \%\left(\mathrm{PM}_{10}\right)$ during the strictest mobility restrictions. Higher $\mathrm{O}_{3}$ concentrations (up to 87\%) were also observed, which is consistent with the response in a VOC-limited chemical regime to the decline in $\mathrm{NO}_{\mathrm{x}}$ emissions. Relative changes with respect to the 2019 observations were consistent with those estimated with the Random Forest model, but indicated that larger decreases in primary pollutants and lower increases in $\mathrm{O}_{3}$ would have occurred. This points out to the need of accounting not only for the differences in emissions, but also in meteorological variables to evaluate the lockdown effects on air quality. The findings of this study may be valuable for formulating emission control strategies that do not disregard their implication on secondary pollutants. The data set used in this study and an introductory machine learning code are openly available at https://data.mendeley.com/datasets/h9y4hb8sf8/1
\end{abstract} (Diaz Resquin et al., 2021). 


\section{Introduction}

In recent times, Machine learning has proved to be an efficient approach to air quality prediction, by relying on historical data to estimate the temporal variability of different pollutants for a specific site at a low computational cost. Also, this kind of model has the ability to unravel underlying patterns in data and deal with complex interactions among predictive variables (Stafoggia et al., 2020).

During the last decade, Random Forest (RF) rose as a new method for the prediction of mean values of atmospheric pollutants (Yu et al., 2016; Feng et al., 2019; Jiang and Riley, 2015). This is a supervised machine learning method, consisting of applying multiple tree classifiers created at random using bagging (i. e., selecting samples stochastically to create new datasets, of which every classification tree is created). Many data science programming languages have libraries where RF is already efficiently implemented (e. g., scikit-learn in Python or randomForest in R). RF is faster and cheaper than other available models, such as regional chemical transport models (CTMs) in terms of computation costs, it needs less input variables and it is a useful method when information on air pollutant concentrations at a particular site is needed. According to Masih (2019), machine learning techniques may even provide better forecasting than CTMs, and out of the different existing algorithms, RF seems to stand out due to its simplicity and the quality of its results. One of the most recent applications of machine learning methods has been aimed at elucidating the interlinkage among the COVID-19 pandemic lockdown measures, human mobility and air quality (Rahman et al., 2021).

The outbreak of the COVID-19 pandemic at the end of 2019, with its devastating consequences in terms of loss of life and economic impact, has caused many governments around the world to impose different degrees of lockdown. For atmospheric scientists, it has also provided a unique opportunity to examine changes in air pollution under decreased emission levels, in an unintentional worldwide experiment. Many studies have, in general, identified significant decreases of most pollutants, except for $\mathrm{O}_{3}$, under the stay-at-home orders imposed against COVID-19 (Muhammad et al., 2020; Faridi et al., 2021; Srivastava, 2021; Grange et al., 2021).

An early approach to analyze the changes in air quality due to the implementation of specific control measures was to comparatively assess concentrations during the lockdown with concentrations of the same period of the previous year or the mean value of a period of five years, using exclusively ground-based or satellite observations. However, the degree to which the COVID-19 lockdown influenced air quality is not only a function of emissions but also of both meteorology and physical and chemical atmospheric transformations (Kroll et al., 2020). In consequence, pure statistical tests or observational comparisons might be inadequate to have a complete understanding of what influences pollutant concentrations, since weather conditions, particle persistence, transport, radiation and seasonality affect concentrations by linear and non-linear processes (Šimić et al., 2020). Another option for such comparison is to use models to simulate a scenario in which restrictions were not implemented. Machine learning methods, including the RF algorithm, have been capable of untangling the changes in pollutant concentrations caused by the COVID-19 lockdown measures of weather-driven variability. Velders et al. (2021) have shown the efficiency of the RF method for this task. With respect to reactive species, the RF method has been also used to assess $\mathrm{O}_{3}$ levels. For example 
Zhan et al. (2018) satisfactorily applied the RF method to predict spatio-temporal variability of daily $\mathrm{O}_{3}$ concentrations across China using information on meteorology, elevation and emission inventories.

The drastic changes in anthropogenic emissions induced by the global pandemic are of major interest to enhance our understanding of the chemistry related to air quality, particularly when the behavior of secondary pollutants, like ozone $\left(\mathrm{O}_{3}\right)$ or components of particulate matter (PM), is explored (Gaubert et al., 2021). $\mathrm{O}_{3}$, in particular, has a complex behavior depending on multiple factors. $\mathrm{NO}_{\mathrm{x}}$ and VOCs play vital roles in the $\mathrm{O}_{3}$ formation process, and its production can be either VOCs-limited or $\mathrm{NO}_{\mathrm{x}}$-limited (Shi and Brasseur, 2020; Liu et al., 2021; Li et al., 2019). In a VOCs-limited regime, $\mathrm{NO}_{\mathrm{x}}$ emission reduction can promote photochemical ozone formation due to the non-linear relationships between $\mathrm{O}_{3}$ and its precursors. On the other hand, in a $\mathrm{NO}_{\mathrm{x}}$-limited regime, reductions in $\mathrm{NO}_{\mathrm{x}}$ concentrations lead to decreasing $\mathrm{O}_{3}$ levels. Also, sometimes any change in VOCs or $\mathrm{NO}_{\mathrm{x}}$ may alter $\mathrm{O}_{3}$ concentrations and it could be referred to as a transitional (or mixed) regime. The goal of this study was twofold: (i) to explore the performance of the RF method in predicting the air quality situation at two monitoring sites of the Metropolitan Area of Buenos Aires (MABA), Argentina and (ii) to apply this method to estimate the changes in air pollutant concentrations under the COVID-19 control measures. We implemented the RF algorithm to estimate the concentrations of $\mathrm{CO}, \mathrm{NO}_{\mathrm{x}}, \mathrm{SO}_{2}, \mathrm{O}_{3}$, and particles with aerodynamic diameter less or equal than $10 \mu \mathrm{m}\left(\mathrm{PM}_{10}\right)$ using meteorological and air quality observations, as well as the local diurnal variation of emissions as explanatory variables. Trained with data acquired in 2019 and 2020 before the start of the pandemic, the RF method can only predict concentrations under a business-as-usual (BAU) scenario. In this research, we comparatively assessed the monitored concentrations during two distinct phases of the COVID-19 lockdown with both the expected concentrations resulting from the BAU RF simulations and the observations registered during the corresponding period in 2019. We also provided the first $\mathrm{O}_{3}$ and $\mathrm{SO}_{2}$ observational datasets in Buenos Aires in more than a decade. In addition, we studied the responses of $\mathrm{O}_{3}$ to the reduction in emissions of its precursors $\left(\mathrm{NO}_{\mathrm{x}}\right.$ and VOCs) because of its relevance regarding emission control and health effects.

The remainder of this paper is structured as follows. Section 2 provides a description of the studied area, the different lockdown phases, the air quality and meteorological data and the structure of the random forest model used to estimate the relative changes (RC) during the lockdown. The evaluation of the model and the analysis of the impact due to the emission reductions are in Section 3. Section 4 provides a description of the data and code availability. Finally, Section 5 presents the main conclusions of this work.

\section{Material and methods}

\subsection{Description of the studied area}

The MABA comprises the Autonomous City of Buenos Aires (ACBA) and 40 surrounding Districts of the Greater Buenos Aires (GBA). Located along the western coast of the Río de la Plata estuary, on a flat plain, the MABA is the third biggest Megalopolis of Latin America and the Caribbean. It has a population of approximately 13 millions, with a heterogeneous population density in the range 14-20 thousands inhab km${ }^{-2}$. Its active fleet reached 5.4 million vehicles by 2019 (Anapolsky, 2020). 
In terms of air pollutant emissions, although road transportation is clearly the largest contributor of CO, VOCs and PM in the area (Castesana et al., 2021), the MABA is also affected by the emissions from residential, commercial and institutional buildings, mainly based on natural gas consumption, and from three power plants, located near the shoreline of the La Plata River, which burn natural gas, gas oil and fuel oil.

\subsection{Description of the lockdown for the MABA}

Argentina's national government established different lockdown phases for the duration of the pandemic (Decree 297/2020, 2020). Since $80 \%$ of Argentina's COVID-19 cases were concentrated in the MABA, some policies applied to the MABA region differed from those applied to the rest of the country. Starting on 20 March 2020, strict measures were imposed to avoid a sharp increase in COVID-19 cases, emphasizing that the population should stay at home and avoid any social contact. All non-essential stores, including toys, furniture and clothing, were closed until 11 May. Table 1 provides a summary of the restrictions set for the MABA during each phase. Under severely restricted mobility, public transport and passenger car circulation decreased drastically. Local mobility dropped down 80\% during the Intense lockdown phase and 65\% for the Flexible lockdown phase until the end of May (Aktay et al., 2020). It is worth noting that, before the COVID-19 pandemic, 1 million vehicles entered the city of Buenos Aires from the suburbs per day.

Considering the different degrees of the restrictions imposed, we evaluated the impact of the lockdown on air quality according to two distinct periods. The first period, from 20 March to 12 April 2020, corresponded to the most restrictive lockdown (LD). The second period, from 13 April to 25 May, was denominated partial lockdown (PLD) because some restrictions were lifted. The period 1-15 March 2020, before the start of the first lockdown, was defined as BLD and was used to evaluate the model. As from 16 March, flexible restrictions started, but were optional, therefore the period 16-19 March was not considered in our research.

Being combustion the main air pollution source in the area, the significant decrease in traffic flow imposed by the lockdown led necessarily to a decrease in the emissions of traffic-related pollutants (D'Angiola et al., 2010; Puliafito et al., 2017; Diaz Resquin et al., 2018; Castesana et al., 2021).

\subsection{Meteorological data and description}

The atmospheric general circulation in the MABA is controlled by the influence of the semi-permanent South Atlantic High pressure system. This system influences the climate of the MABA throughout the year by bringing in moist winds from the northeast, which produce most of the precipitation in the area in the form of frontal systems, or storms produced by cyclogenesis, in autumn and winter (Barros et al., 2006). In terms of the climate conditions of the MABA, temperatures at the beginning of autumn range from warm to hot in the afternoon, but they are mild in the nights and the mornings. Later on in the season, conditions are cooler, featuring mild afternoons, and cold nights and mornings.

To identify similarities and differences between the meteorological conditions during the lockdown phases and the testing period (BLD, LD and PLD) with those of the autumn of 2019 (March, April and May, MAM2019) we carried out a meteorological analysis for all periods. We used hourly and daily data from the Buenos Aires Central Observatory (OBS: Lat: $34^{\circ} 35^{\prime}$ S 
Table 1. Description of the lockdown phases on the MABA. NU Not used (Not included in the model)

\begin{tabular}{|c|c|c|c|c|}
\hline Initial Date & Phase & Denomination & Description & Mobility \\
\hline 1 March 2020 & $\begin{array}{l}\text { Before the lock- } \\
\text { down }\end{array}$ & BLD & $\begin{array}{l}\text { Pandemic had started in South America but no restrictions were thus } \\
\text { far implemented in Argentina. }\end{array}$ & $100 \%$ \\
\hline 16 March 2020 & $\begin{array}{l}\text { School Closedown } \\
\text { and Optional Lock- } \\
\text { down }\end{array}$ & $\mathrm{NU}$ & $\begin{array}{l}\text { Countrywide, all schools and universities were closed. People were } \\
\text { advised to stay at home. Theaters and cinemas were shut. Public } \\
\text { events over } 200 \text { people were cancelled. Implementing home-office } \\
\text { was recommended. Gatherings were to be avoided. }\end{array}$ & $90 \%$ \\
\hline 20 March 2020 & Strict Lockdown & $\mathrm{LD}$ & $\begin{array}{l}\text { Bars, restaurants, shopping centers and stores in general were } \\
\text { closed, with the exception of food and medicine stores. Only essen- } \\
\text { tial economic activities were permitted. Circulation of passenger ve- } \\
\text { hicles was only allowed with a special permit. Public transport was } \\
\text { limited within the region. Most industrial activities were suspended. } \\
\text { Only groceries were allowed to be delivered. These restrictions ap- } \\
\text { ply countrywide, regardless of the amount of cases informed. The } \\
\text { country and the district borders were closed. }\end{array}$ & $20 \%$ \\
\hline 31 March 2020 & $\begin{array}{l}\text { Flexible Lockdown } \\
\text { I }\end{array}$ & LD & Food delivery was permited. & $20 \%$ \\
\hline 13 April 2020 & $\begin{array}{l}\text { District Differenti- } \\
\text { ated Lockdown I }\end{array}$ & PLD & $\begin{array}{l}\text { More economic activities were permitted. More stores were permit- } \\
\text { ted to open in several districts. The lockdown in the MABA contin- } \\
\text { ued, but people started to be less careful about the social distancing } \\
\text { measures. }\end{array}$ & $35 \%$ \\
\hline
\end{tabular}

Lon: $58^{\circ} 29^{\prime} \mathrm{W}$ ). The site of the Meteorological Weather Service of Argentina is located in a residential area. It is representative of the meteorology of the air quality conditions under study.

Average temperatures in the $\operatorname{BLD}\left(24.4^{\circ} \mathrm{C}\right)$ and in the $\operatorname{LD}\left(21.1^{\circ} \mathrm{C}\right)$ were higher than that in MAM2019 $\left(18{ }^{\circ} \mathrm{C}\right)$ while the average temperature in the PLD $\left(16.8^{\circ} \mathrm{C}\right)$ was lower than that in MAM2019 but close to the corresponding value in May 2019 $\left(16^{\circ} \mathrm{C}\right)$. Precipitation in March and April 2020 exceeded the accumulated values of the same months of $2019(+60 \%$ and + 90\% respectively). On the contrary, precipitation in May 2020 exhibited significantly lower values than those of 2019 (-75\%).

During MAM2019, the average calm value was 6.7\%, while during the BLD, the LD and the PLD, the corresponding calm values were $3.6 \%, 4.7 \%$ and $8.6 \%$. Average wind velocity, within the range $7.5-8.6 \mathrm{~km} \mathrm{~h}^{-} 1$, was similar in all periods. In 
https://doi.org/10.5194/essd-2021-318

Preprint. Discussion started: 13 October 2021

(c) Author(s) 2021. CC BY 4.0 License.

(c) (1)

autumn 2020, the prevailing wind was from the NW-N sector with an average contribution of $34 \%$ against $26.5 \%$ in 2019 . The LD and the PLD periods had a similar direction of prevailing winds as autumn 2019, contrarily $45 \%$ of winds during the BLD were from the NE-E sector.

Our analysis showed that there were meteorological differences in terms of temperature and precipitation between autumn 2019 and the periods analyzed in 2020 (BLD, LD, and PLD). This is indicative of the need of taking into account the influence of meteorological conditions for comparative purposes of air quality conditions that occurred in different periods.

\subsection{Air quality data}

We employed air quality data from two monitoring sites: Comisión Nacional de Energía Atómica (CNEA), operated by our research group, and Parque Centenario (PC), managed by the Autonomous City of Buenos Aires (described below). Both sites are mostly influenced by the emissions from mobile and residential sources, and, to a lesser extend, by the thermal power plants, located at least at $6 \mathrm{~km}$ from them (Diaz Resquin et al., 2018; Pineda Rojas et al., 2020).

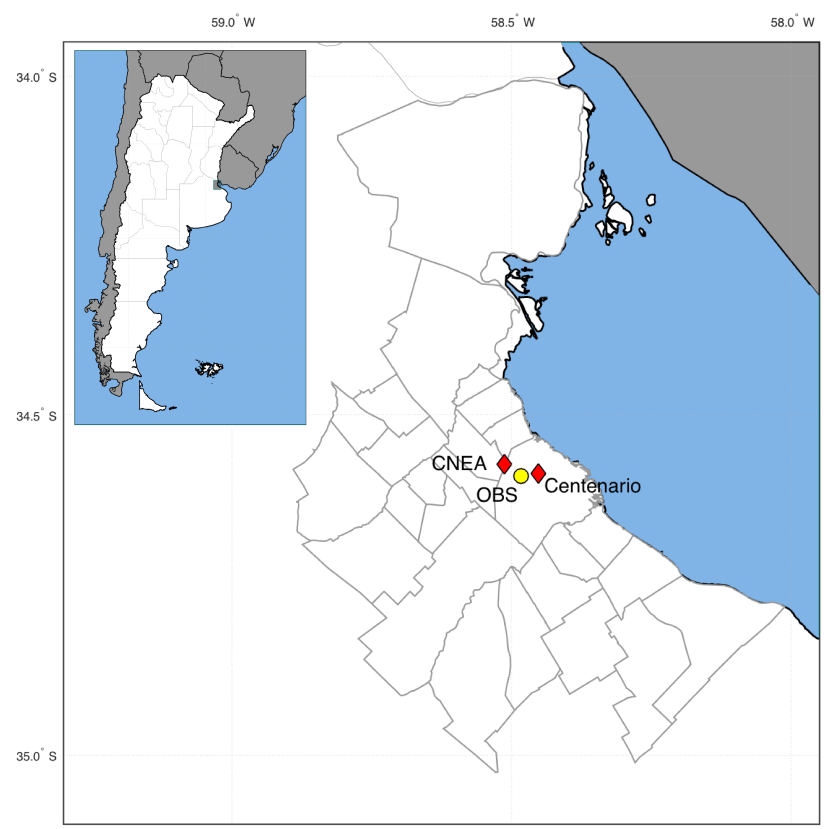

Figure 1. Location of MABA in Argentina (top left); zoom of the MABA(right). In yellow, the location of OBS, the site of the National Meteorological Service monitoring site referred in this study, and in red, the air quality monitoring sites (Shape files from IGN). 
https://doi.org/10.5194/essd-2021-318

Preprint. Discussion started: 13 October 2021

(c) Author(s) 2021. CC BY 4.0 License.

(c) (i)

\subsubsection{Comisión Nacional de Energía Atómica}

From 23 February 2019 to 26 May 2020 a monitoring campaign was carried out in an open area $\left(-34.57{ }^{\circ} \mathrm{S},-58.51^{\circ} \mathrm{W}\right)$ situated $14 \mathrm{~km}$ away from the Buenos Aires City center (Figure 1) to assess the levels of different gases (CO, NO, $\mathrm{NO}_{2}, \mathrm{SO}_{2}$, and $\mathrm{O}_{3}$ ) and their temporal variability in a residential area of the MABA.

The main goal of this monitoring campaign was to assess the temporal variability of $\mathrm{SO}_{2}$ and $\mathrm{O}_{3}$ in the area for an entire year. Although it may seem surprising, especially for a megacity like the MABA, there is scarce and fragmentary information on the concentrations of $\mathrm{SO}_{2}$ and $\mathrm{O}_{3}$ for this large urban conglomerate. Presently, $\mathrm{O}_{3}$ is routinely monitored in only one site of the MABA, located in an industrial area. Past data for the region are only available from a few short-time campaigns carried out in the early 2000s (Reich et al., 2006). Similarly, there is a lack of monitored $\mathrm{SO}_{2}$ concentrations because historical measurements carried out in the 1990s reported very low values, and therefore decision makers decided not to measure this pollutant on a regular basis. However, it has now become a pollutant of concern for local authorities that have recently decided to start monitoring $\mathrm{SO}_{2}$ in two of the four air quality stations of the ACBA.

Air pollutant concentrations were continuously acquired as described in Table 2. Monitors were placed at an approximate height of $10 \mathrm{~m}$, and $100 \mathrm{~m} \mathrm{E}$ from a main traffic artery with a high density of buses, light duty trucks and passenger cars. Another main artery is located $500 \mathrm{~m} \mathrm{~N}$, having circulation of vehicles including trucks and buses in a low speed stop-and-go pattern. The international airport Jorge Newbery, two thermal power plants and the La Plata river are located within a $19 \mathrm{~km}$ radius of the monitoring station.

Data was registered per one minute averages. Unfortunately, from 26 May onwards, restrictions on entering our institute where the monitoring station was located led to the need to suspend the monitoring campaign.

\subsubsection{Parque Centenario}

To include aerosol variations in this analysis and complement the information of CNEA's site, we used $\mathrm{PM}_{10}, \mathrm{CO}, \mathrm{NO}$, and $\mathrm{NO}_{2}$ data from $\mathrm{PC}$ station $\left(34.61^{\circ} \mathrm{S}, 58.44^{\circ} \mathrm{W}\right.$ ), one of the surface air quality sites of the Environmental protection agency of Buenos Aires city (APRA). This site is located in a residential-commercial area with medium vehicular flow and relatively low incidence of stationary sources. A monthly technical report of the hourly-average concentrations registered in PC is available at APRA website (APRA, 2020). Although the city has three other monitoring stations, at least one of the essential periods needed for this study was missing in each of them. Therefore, they did not serve our purpose.

\subsubsection{Summary of the datasets}

Relatively low concentration values for all the analyzed periods, with no exceedances for short term air quality standard for all the pollutants measured (Decree 1074/18, 2018; Act 1356, 2004) were registered in both sites. Air pollutants, except $\mathrm{SO}_{2}$, exhibited well defined diurnal cycles. 
https://doi.org/10.5194/essd-2021-318

Preprint. Discussion started: 13 October 2021

(c) Author(s) 2021. CC BY 4.0 License.

(c) (1)

Table 2. Description of the equipment used in CNEA site

\begin{tabular}{|c|c|c|c|}
\hline Pollutant & Instrument & Description & Calibration* \\
\hline $\mathrm{CO}$ & $\begin{array}{l}\text { Horiba } \\
\text { APMA-370 }\end{array}$ & $\begin{array}{l}\text { Sampler with a non-dispersive } \\
\text { infrared absorption photometry } \\
\text { sensor with a solenoid valve } \\
\text { with cross flow modulation. }\end{array}$ & $12.44 \mathrm{ppmV}$ \\
\hline $\mathrm{O}_{3}$ & $\begin{array}{l}\text { Horiba } \\
\text { APOA-370 }\end{array}$ & $\begin{array}{l}\text { Detector that operates with a } \\
\text { cross flow modulation, ultra- } \\
\text { violet absorption method in } \\
\text { conjunction with the compara- } \\
\text { tive calculation method. }\end{array}$ & $\begin{array}{l}0.1 \mathrm{ppmV} . \pm \\
0.5 \% \text { diluted }\end{array}$ \\
\hline $\mathrm{SO}_{2}$ & $\begin{array}{l}\text { Horiba } \\
\text { APSA-370 }\end{array}$ & UV Fluorescence detector. & $\begin{array}{lr}0.05 \quad \mathrm{ppmV} \\
\pm \quad 0.6 \% \\
\text { diluted }\end{array}$ \\
\hline $\mathrm{NO} / \mathrm{NO}_{2}$ & $\begin{array}{l}\text { Horiba } \\
\text { APNA-370 }\end{array}$ & $\begin{array}{l}\text { Cross flow modulation type } \\
\text { with reduced chemilumines- } \\
\text { cence detector. }\end{array}$ & $\begin{array}{l}0.099 \mathrm{ppmV} \\
\pm 1.4 \% \quad \mathrm{di}- \\
\text { luted (NO) }\end{array}$ \\
\hline
\end{tabular}

\footnotetext{
* The calibration of the ambient air gases detectors was performed by following U.S. EPA regulations and Horiba standard procedures (see U.S. EPA CFR 40 Part 50, appendixes A1, C, D and F, and the corresponding user manual for the Horiba AP devices). The APMA-370, APSA-370 and APNA-370 were calibrated using EPA certified calibration gases and diluted with an Environics 6103, a NIST traceable mass flow controller dilutor, when needed.
}

$\mathrm{CO}$ and $\mathrm{NO}_{\mathrm{x}}$ patterns were governed by traffic emissions (Figs. S1 and S2 of Supplementary Material), with the maximum values in winter. Annual mean average values of $\mathrm{NO}_{\mathrm{x}}$ were $\sim 37 \mathrm{ppb}$ for both CNEA and PC. Relevant differences in $\mathrm{CO}$ were identified, with annual mean levels in PC doubling those measured in CNEA (0.51 ppm versus $0.26 \mathrm{ppm}$ ).

$\mathrm{PM}_{10}$, which was only measured in $\mathrm{PC}$, had a mean value of $21 \mu \mathrm{g} \mathrm{m}{ }^{-3}$, with the maximum values at noon.

With respect to the pollutants that were only measured in $\mathrm{CNEA}, \mathrm{SO}_{2}$ maximum concentrations were registered during autumn (April) with monthly averages in the range 2-2.9 ppb. In terms of $\mathrm{O}_{3}$ concentrations, maximum daylight levels were registered during summer. The diurnal cycle presented higher levels during the afternoon and was opposite to that of $\mathrm{NO}_{\mathrm{x}}$.

\subsection{Air pollution estimations}

We used the machine learning RF method to estimate the hypothetical pollutant concentrations that would have occurred in the MABA during the LD and the PLD phases if no lockdown measures had been imposed (BAU scenario). We selected the RF algorithm based on its demonstrated ability to separate the effects of meteorology and chemical reactions from the COVID-19 driven decrease in emissions (Zhan et al., 2018; Rahman et al., 2021; Velders et al., 2021). RF requires a short training time 
https://doi.org/10.5194/essd-2021-318

Preprint. Discussion started: 13 October 2021

(c) Author(s) 2021. CC BY 4.0 License.

(c) (1)

and can provide reliable information on air quality, with a strong anti-overfitting ability (Liu et al., 2021). Relations between different pollutants can also be easily included, which is of particular interest for those that have a very complex chemistry, such as $\mathrm{O}_{3}$. It is also easy to adapt the methodology to different time periods and sites. The schematic of the model building process can be seen in Fig. 2.

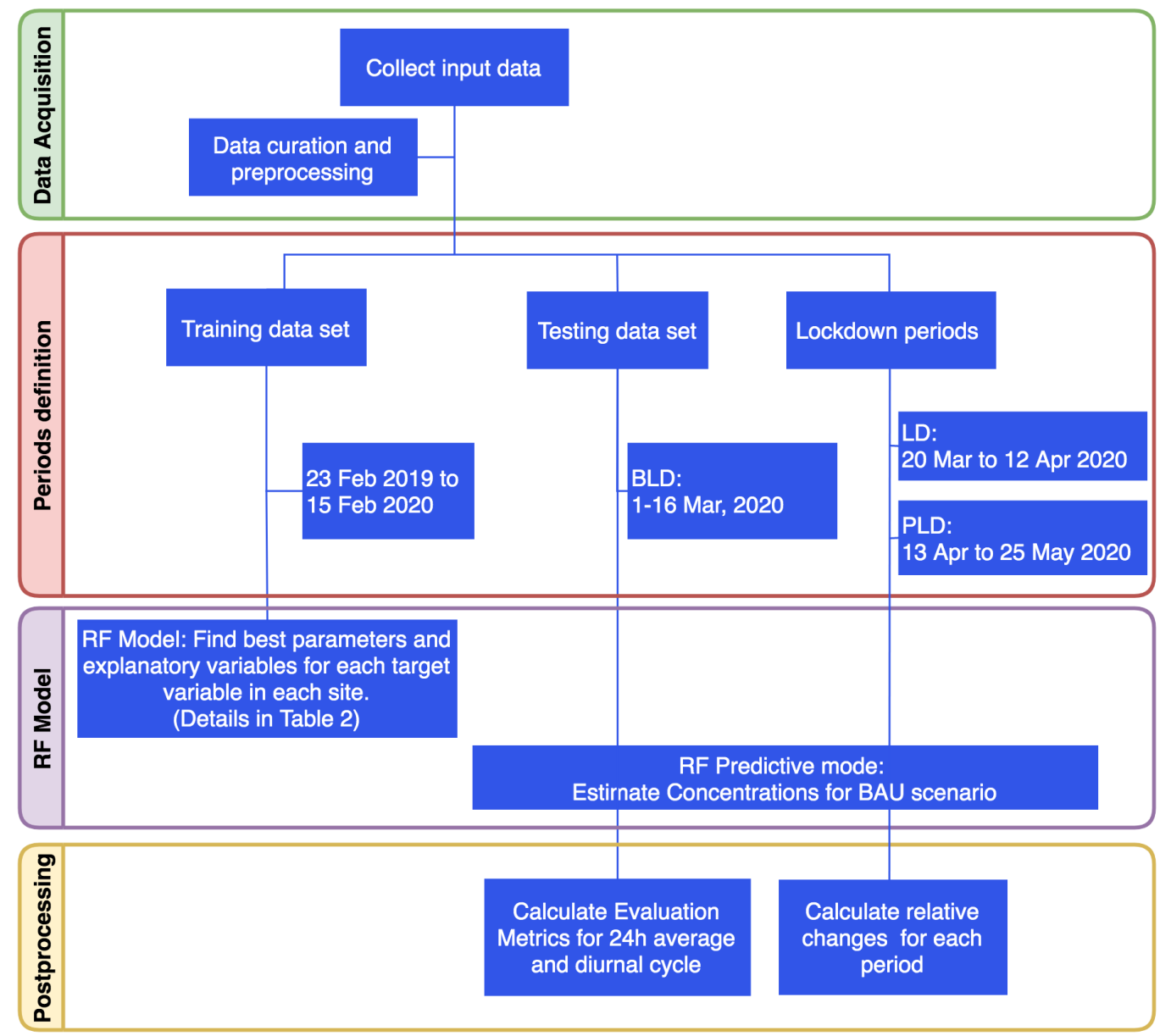

Figure 2. Schematic description of model building and evaluation.

Observations from February 2019 to May 2020 were divided in two different groups: before and after the start of the lockdown. The first group of observations, from February 2019 to February 2020, was used to train and test the RF model (80\%-20\% split ratio respectively). From 1 March to 25 May 2020, the model was used in predictive mode to estimate pollutant concentrations under the BAU scenario. The BLD period was established as a evaluation period in order to check the adequate 
Table 3. Random Forest model. Target variables and predictors.

\begin{tabular}{cllcc}
\hline \multirow{2}{*}{ Site } & $\begin{array}{l}\text { Target } \\
\text { Variable }\end{array}$ & Explanatory Variables & ntree & mtry \\
\hline \multirow{2}{*}{ CNEA } & $\mathrm{CO}$ & t2, rh2, U, V, gasoline diurnal cycle & 1000 & 3 \\
& $\mathrm{NO}$ & t2, rh2, U, V, gasoline and diesel diurnal cycles & 1500 & 3 \\
& $\mathrm{NO}_{2}$ & t2, U, V, gasoline diurnal cycle, $\mathrm{CO}, \mathrm{NO}$ & 1000 & 3 \\
& $\mathrm{SO}_{2}$ & wspd, daynight, $\mathrm{CO}, \mathrm{NO}, \mathrm{NO}_{2}$ & 1000 & 3 \\
& $\mathrm{O}_{3}$ & $\mathrm{U}, \mathrm{V}$, daynight, $\mathrm{CO}, \mathrm{NO}, \mathrm{NO}_{2}, \mathrm{SO}_{2}$ & 2000 & 3 \\
$\mathrm{PC}$ & $\mathrm{CO}$ & t2, wspd, wdir, gasoline diurnal cycle & 1000 & 2 \\
& $\mathrm{NO}$ & t2, rh2, slp, U, V, calm, gasoline diurnal cycle & 1000 & 3 \\
& $\mathrm{NO}_{2}$ & t2, U, V, gasoline diurnal cycle, $\mathrm{NO}$ & 1000 & 3 \\
& $\mathrm{PM}_{10}$ & wspd, diesel diurnal cycle, $\mathrm{NO}, \mathrm{NO}_{2}$ & 1000 & 3 \\
\hline
\end{tabular}

rh2: $2 \mathrm{~m}$ relative humidity; slp: sea level pressure; $t 2: 2 \mathrm{~m}$ temperature; $\mathrm{U}: 10 \mathrm{~m} \mathrm{U}$ component of winds; $\mathrm{V}: 10 \mathrm{~m} \mathrm{~V}$ component of winds; wdir: 10m wind direction; wspd: $10 \mathrm{~m}$ wind speed; ntree: Number of trees to grow and mtry: Number of variables randomly sampled as candidates at each split.

performance of the model. From 20 March to 25 May, RF estimates were compared to observations in order to quantify and interpret the changes during the LD and the PLD.

Measured air pollutant concentrations were the target variables for each monitoring site, namely $\mathrm{NO}, \mathrm{CO}, \mathrm{NO}_{2}, \mathrm{O}_{3}$, and $\mathrm{SO}_{2}$ (CNEA) and $\mathrm{NO}, \mathrm{CO}, \mathrm{NO}_{2}$, and $\mathrm{PM}_{10}$ (PC). The available predictive variables were wind speed, wind direction, surface temperature, sea level pressure, relative humidity, the pollutant concentrations available in each of the sites, and a variable called daynight that can have values as morning, afternoon or night. Wind speed and wind direction data were used to derive the $\mathrm{U}$ and $\mathrm{V}$ wind components to avoid model continuity errors at 0 and 360 degrees. The calm condition and the sine of wind direction were also tested as predictors. Diurnal emission cycles for pollutants associated with gasoline and diesel emissions were added to improve the agreement in the testing period with the variations throughout the day, as published by Castesana et al. (2021). Both cycles were tested for each pollutant. Weekly patterns used were taken from PREP-CHEM (Freitas et al., 2011). All meteorological and air quality variables, as well as emission cycles, were tested as explanatory variables for each pollutant, and those performing the best during testing were selected. In general, a combination of meteorological variables was identified as explanatory variables for $\mathrm{CO}, \mathrm{NO}$, and $\mathrm{NO}_{2}$, with the subset $\{$ temperature, relative humidity, $\mathrm{U}$, and $\mathrm{V}$ \} exhibiting the most relevant role. Wind speed was only relevant for $\mathrm{SO}_{2}$ (CNEA), $\mathrm{CO}$, and $\mathrm{PM}_{10}$ (PC), while wind direction resulted as an explanatory variable for $\mathrm{CO}$ in PC only. The only meteorological variables relevant for $\mathrm{O}_{3}$ were $\mathrm{U}$,V. Noticeably, the diurnal cycle of gasoline vehicles was needed for $\mathrm{CO}, \mathrm{NO}$, and $\mathrm{NO}_{2}$ for both sites, while the diurnal cycle of diesel was required only for $\mathrm{NO}(\mathrm{CNEA})$ and $\mathrm{PM}_{10}(\mathrm{PC})$. Not surprisingly, $\mathrm{O}_{3}$ prediction was most dependent on the variable daynight and the simulated concentrations of the other pollutants, including $\mathrm{SO}_{2}$, but excluding $\mathrm{PM}_{10}$. Table 3 presents the final set of predictive variables used in the RF model that best reproduced the observations during the BLD for each target variable. 


\subsection{Random Forest model evaluation}

The RF model was tested during the BLD for adequate performance, focusing on the reproduction of: (i) the mean value, (ii) the mean diurnal cycles and (iii) the $24 \mathrm{~h}$ average concentration.

For each pollutant, differences between the mean value resulting from the $\operatorname{RF}(\bar{M})$ and that from the observations $(\bar{O})$ were assessed using the ratio between these two values $(\bar{M} / \bar{O})$. Diurnal cycles were comparatively assessed by graphical inspection of the temporal series of the mean values and spreads of the modelled and observed concentrations of each pollutant, as well as the Pearson correlation coefficient $(r)$. Daily average concentrations were assessed considering the normalized mean bias $(N M B)$, the Pearson correlation coefficient and the mean fractional bias $(M F B)$.

$N M B=\frac{1}{N} \sum_{k=1}^{N} \frac{M_{k}-O_{k}}{O_{k}} \times 100$

$220 \quad r=\frac{1}{N-1} \sum_{k=1}^{N}\left(\frac{M_{k}-\bar{M}}{\sigma_{M}}\right)\left(\frac{O_{k}-\bar{O}}{\sigma_{O}}\right)$

$M F B=\frac{2}{N} \sum_{k=1}^{N}\left(\frac{O_{k}-M_{k}}{O_{k}+M_{k}}\right) \times 100$

The $N M B$ is useful for comparing pollutants that cover different concentration scales and it is defined as the difference between modeled and observed mean concentrations normalized by dividing by the mean observed concentration for that period. The $\mathrm{r}$ coefficient is useful to measure the linear relationship between two variables. The $M F B$ is a measure of mean relative bias and indicates systematic errors (Borrego et al., 2008).

Finally, bivariate polar plots were built considering observations and RF results, using the openair library of the R programming language (Carslaw and Ropkins, 2012; R Core Team, 2019).

\section{Results and discussion}

\subsection{Evaluation of the results of the Random Forest model}

In general, modelled $\mathrm{CO}, \mathrm{NO}, \mathrm{NO}_{2}, \mathrm{NO}_{\mathrm{x}}$ and $\mathrm{PM}_{10}$ concentrations in both sites were in good agreement with the corresponding observations (see Table 4 and Figs. 3 and 4). For the CNEA site, $N M B$ showed a bias $<10 \%$ for all the pollutants and $M F B$ of the daily concentrations was between $-5.8 \%(\mathrm{NO})$ and $12 \%(\mathrm{CO})$. For PC, $N M B$ was between $-1.2 \%\left(\mathrm{PM}_{10}\right)$ and $8.6 \%$ (NO). Our results showed that the model tended to slightly overpredict the concentrations of all the pollutants except for $\mathrm{NO}$ in CNEA and $\mathrm{NO}_{2}$ and $\mathrm{PM}_{10}$ in PC. $M F B$ of the daily concentrations was between $1.1 \%\left(\mathrm{PM}_{10}\right)$ and 9.2\% (NO). Calculations of diurnal cycles utilizing RF outcomes reproduced adequately the bimodal behavior during BLD. The agreement was best for $\mathrm{NO}_{2}$, where the Pearson correlation coefficient $\left(r_{d c}\right)$ was 0.89 for both sites while all other $r_{d c}$ were above 0.74 . As shown in Figs. 5 and 6, the RF model adequately reproduced the BLD daily concentrations for all the emitted pollutants. 
Table 4. Summary of the evaluation statistics used in Random Forest for the testing period (BLD). $N M B$ and $M F B$ are presented in percentage for the daily mean concentrations (d) and Pearson Correlation coefficient for diurnal cycle (dc).

\begin{tabular}{llcccc}
\hline & & $\left(\frac{\bar{M}}{O}\right)_{B L D}$ & $N M B_{d}[\%]$ & $r_{d c}$ & $M F B_{d}[\%]$ \\
\hline PC & $\mathrm{CO}$ & 1.04 & 4.0 & 0.81 & 6 \\
& $\mathrm{NO}_{\mathrm{x}}$ & 1.03 & 3.3 & 0.77 & 5.5 \\
& $\mathrm{NO}$ & 1.08 & 8.6 & 0.74 & 9.2 \\
& $\mathrm{NO}_{2}$ & 1.00 & -0.4 & 0.89 & 3.2 \\
& $\mathrm{PM}_{10}$ & 0.98 & -1.2 & 0.78 & 1.1 \\
$\mathrm{CNEA}$ & $\mathrm{CO}$ & 1.10 & 10 & 0.76 & 12 \\
& $\mathrm{NO}$ & 1.01 & 1.2 & 0.76 & 3.3 \\
& $\mathrm{NO}_{\mathrm{x}}$ & 0.98 & -1.3 & 0.64 & -5.8 \\
& $\mathrm{NO}_{2}$ & 1.03 & 3.4 & 0.89 & 6.3 \\
& $\mathrm{SO}_{2}$ & 1.04 & 3.8 & 0.65 & 4.3 \\
& $\mathrm{O}_{3}$ & 1.08 & 7.1 & 0.80 & 7.3 \\
\hline
\end{tabular}
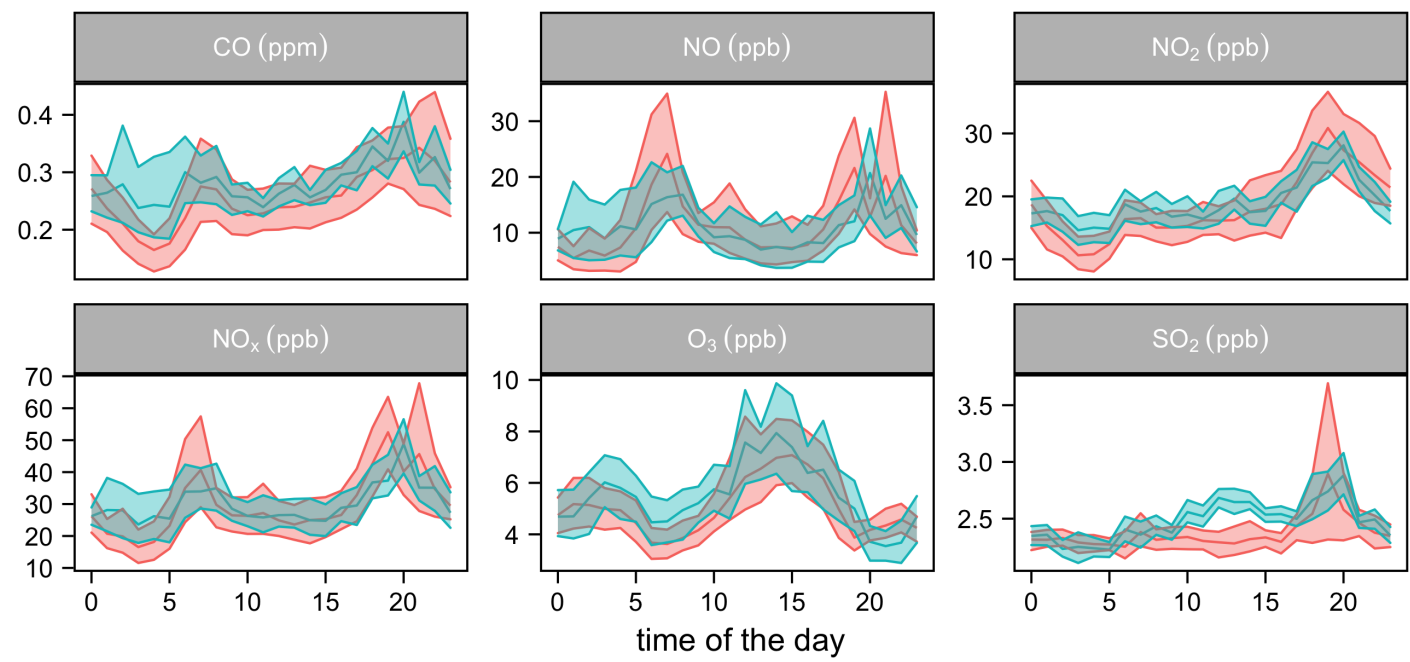

observations

Random Forest

Figure 3. Diurnal cycles for the testing period (from 1 March 2020 to 15 March 2020) for CNEA. The line represents the average diurnal cycle and the shaded area represents the standard deviation.

Results for $\mathrm{O}_{3}$ were also satisfactory, particularly considering its secondary nature with complex dynamics depending on multiple factors such as radiation energies, VOC and $\mathrm{NO}_{\mathrm{x}}$ concentrations and their ratio (Seinfeld and Pandis, 1998). Model 

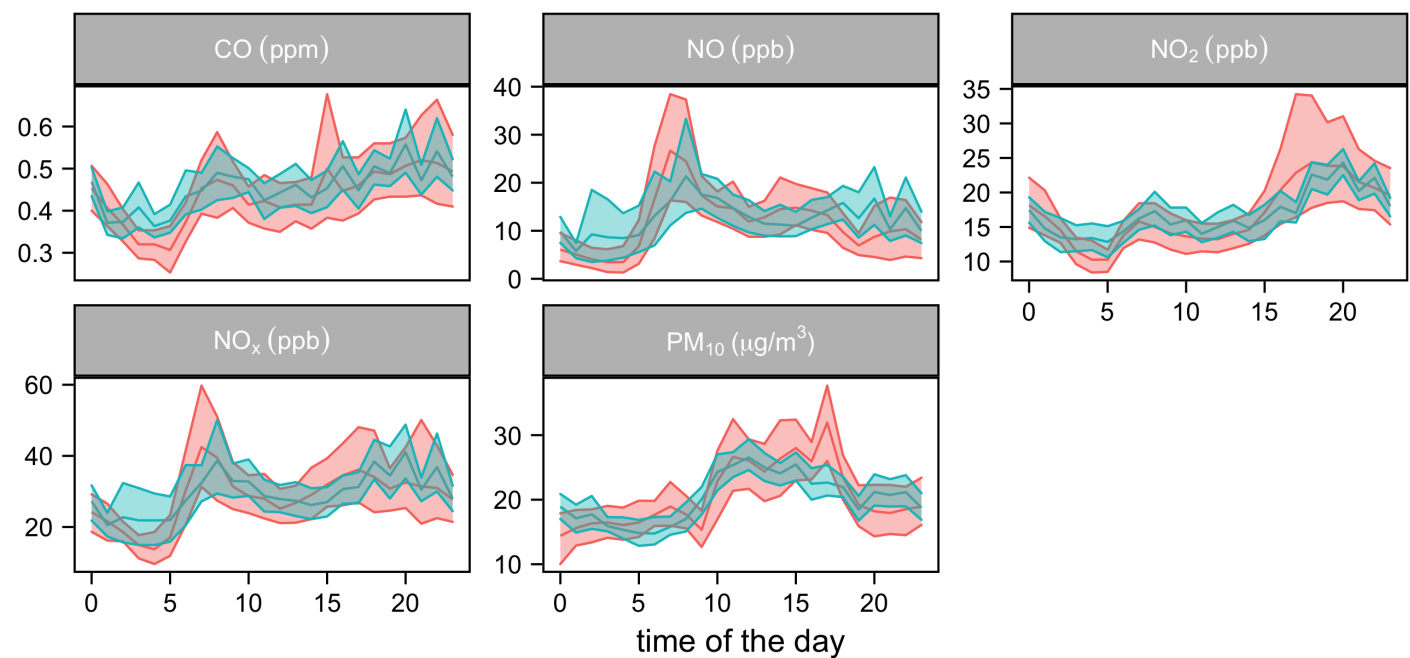

observations

Random Forest

Figure 4. Diurnal cycles for the testing period (from 1 March 2020 to 15 March 2020) for PC. The line represents the average diurnal cycle and the shaded area represents the standard deviation.

performance indicators were $N M B=7.1 \%$ and $r_{d c}=0.80$. Other processes involved in $\mathrm{O}_{3}$ chemistry (like the ratios $\mathrm{O}_{3} /$ VOCs and $\mathrm{O}_{3} / \mathrm{NO}_{\mathrm{x}}$ ) in the MABA were analyzed, as a further way to test the RF model performance. The ratio $\mathrm{O}_{3}-\mathrm{CO}$ was used as a proxy for VOCs, because direct VOCs observations were unavailable in the MABA and traffic-borne VOCs are intimately linked to CO (Bon et al., 2011; Cazorla et al., 2020). Overall, $100 \%$ of $\mathrm{O}_{3}-\mathrm{CO}, \mathrm{O}_{3}-\mathrm{NO}_{2}$ and $\mathrm{O}_{3}-\mathrm{NO}_{\mathrm{x}}$ and $73 \%$ of $\mathrm{O}_{3}-\mathrm{NO}$ daily ratios from RF were within a factor of 2 of those resulting from the observations (see Figure S4). The Pearson correlation coefficients $(r)$ between observed and estimated $\mathrm{O}_{3}-\mathrm{CO}$ and $\mathrm{O}_{3}-\mathrm{NO}_{\mathrm{x}}$ daily ratios were found to be 0.79 and 0.89 respectively. In this context, this model was suitable to reproduce not only the levels of primary contaminants in the two analyzed sites, but also the formation of $\mathrm{O}_{3}$ at the CNEA site. On the other hand, higher discrepancies were found for $\mathrm{SO}_{2}\left(r_{d c}=0.65\right)$ although $N M B<4 \%$. The diurnal cycle of $\mathrm{SO}_{2}$, which has been identified to be highly linked to diesel trucks (D'Angiola et al., 2010), had a sharp peak between 18:00 and 20:00 that could not be entirely captured by the model. Concentrations from 12:00 to 17:00 were also overestimated. Bivariate polar plots showed a similar pattern for the RF results and the BLD observations for all pollutants (Figures S6 and S7).

\subsection{Quantifying and analyzing the changes in concentrations during the lockdown periods}

In this discussion we compare the concentrations that were measured during the LD and the PLD phases with the corresponding BAU concentrations estimated by the RF model and/or the observations during MAM2019. The corresponding 

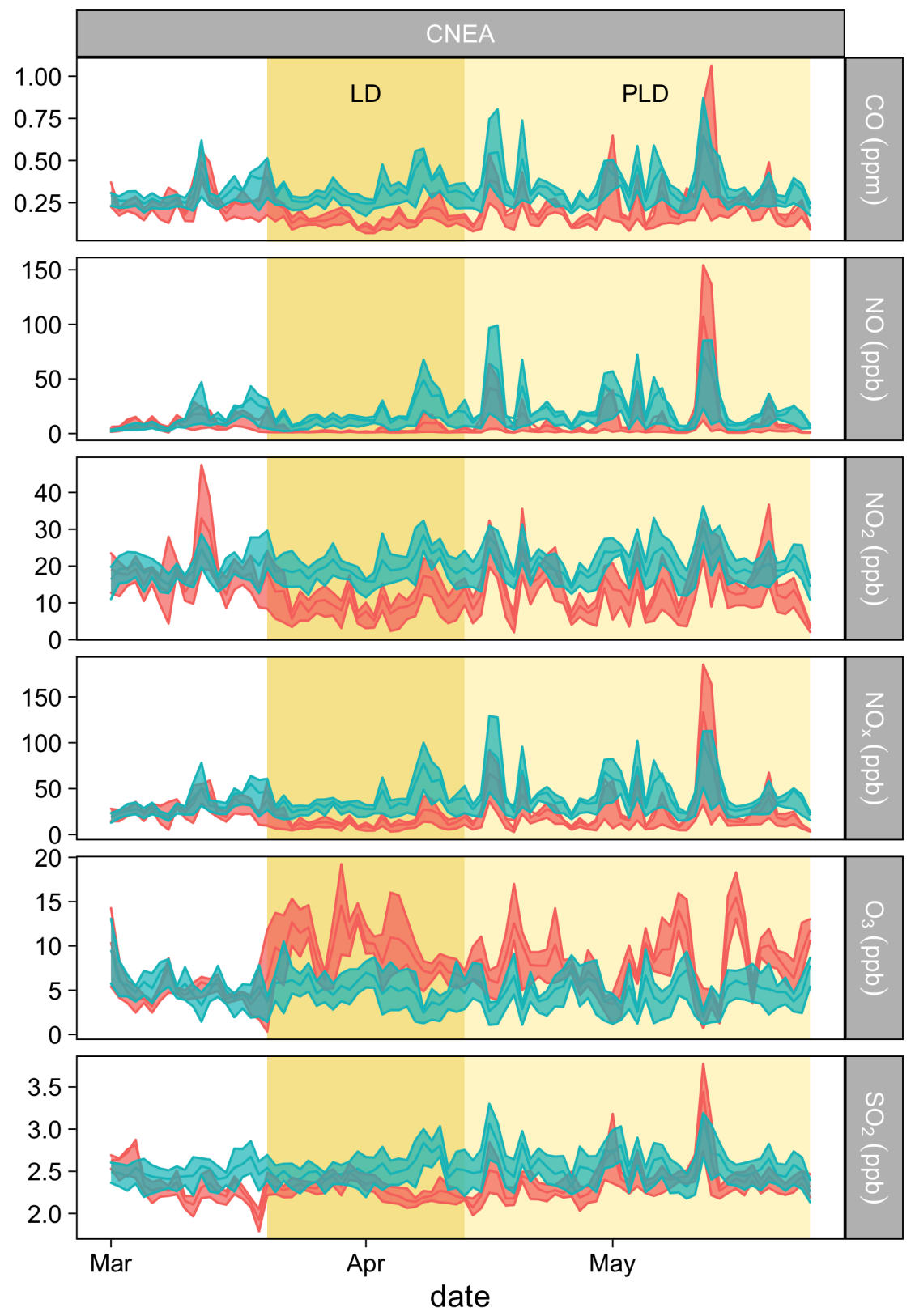

Observations

BAU Scenario (RF)

Figure 5. Average daily concentrations for CNEA site. The line represents the $24 \mathrm{~h}$ average concentration and the shaded area represents the daily levels between the 25 and 75 percentile. 

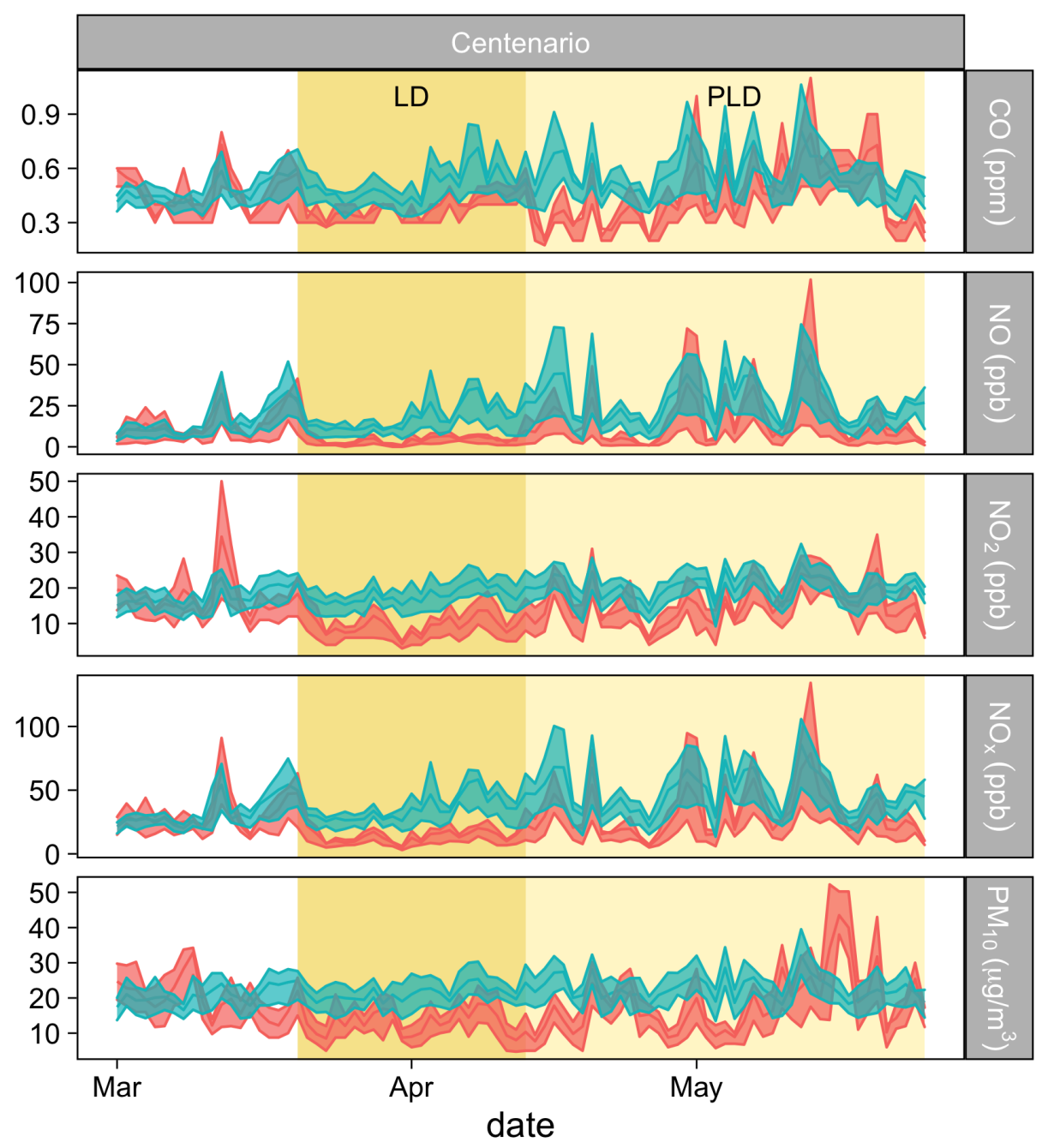

Observations $\square$ BAU Scenario (RF)

Figure 6. Average daily concentrations for PC site. The line represents the $24 \mathrm{~h}$ average concentration and the shaded area represents the daily levels between the 25 and 75 percentile.

percent relative changes $\left(\mathrm{RC}_{\mathrm{RF}}\right.$ or $\left.\mathrm{RC}_{\mathrm{obs} 2019}\right)$ were estimated on the basis of Eqs. 4 and 5, respectively.

$\mathrm{RC}_{\mathrm{RF}}[\%]=\frac{\text { Period }_{o b s 2020}-\text { Period }_{R F}}{\text { Period }_{R F}} \times 100$

$\mathrm{RC}_{\mathrm{obs} 2019}[\%]=\frac{\text { Period }_{\text {obs } 2020}-\mathrm{MAM}_{2019_{o b s}}}{\text { MAM2019 }} \times 100$ 
Table 5. Summary of the concentrations and relative changes for the LD and the PLD for PC and CNEA sites compared with Random Forest (RF) and March-April-May 2019 (MAM2019) Observations. In every case, the RC were calculated considering the mean value for each period.

\begin{tabular}{|c|c|c|c|c|c|c|c|c|c|c|c|}
\hline & \multirow{3}{*}{\multicolumn{2}{|c|}{$\begin{array}{l}\text { BLD } \\
\qquad M B_{d}[\%]\end{array}$}} & \multirow{3}{*}{$\begin{array}{c}\text { MAM2019 } \\
\text { Conc. } \\
\text { obs }\end{array}$} & \multicolumn{4}{|c|}{ LD } & \multicolumn{4}{|c|}{ PLD } \\
\hline & & & & \multicolumn{2}{|c|}{ Conc. } & \multicolumn{2}{|r|}{$\mathrm{RC}[\%]$} & \multicolumn{2}{|c|}{ Conc. } & \multicolumn{2}{|c|}{$\mathrm{RC}[\%]$} \\
\hline & & & & obs & $\mathrm{RF}$ & $\mathrm{RF}$ & MAM2019 & obs & $\mathrm{RF}$ & $\mathrm{RF}$ & MAM2019 \\
\hline \multicolumn{12}{|l|}{$\mathrm{PC}$} \\
\hline $\mathrm{CO}(\mathrm{ppm})$ & 0.02 & 4.0 & 0.54 & 0.39 & 0.50 & -22 & -28 & 0.45 & 0.57 & -21 & -17 \\
\hline $\mathrm{NO}_{\mathrm{x}}(\mathrm{ppb})$ & 1.12 & 3.3 & 41.7 & 15.0 & 35.9 & -58 & -64 & 30.7 & 47.4 & -35 & -26 \\
\hline NO (ppb) & 1.09 & 8.6 & 22.9 & 5.2 & 17.8 & -71 & -77 & 15.2 & 27.3 & -44 & -34 \\
\hline $\mathrm{NO}_{2}(\mathrm{ppb})$ & 0.04 & -0.4 & 18.8 & 9.8 & 18.1 & -46 & -48 & 15.5 & 20.1 & -23 & -18 \\
\hline $\mathrm{PM}_{10}\left(\mu \mathrm{gm}^{-3}\right)$ & -0.33 & -1.2 & 22.0 & 13.6 & 21.3 & -36 & -38 & 18.4 & 22.8 & -19 & -16 \\
\hline \multicolumn{12}{|l|}{ CNEA } \\
\hline $\mathrm{CO}(\mathrm{ppm})$ & 0.03 & 10.0 & 0.35 & 0.17 & 0.32 & -47 & -51 & 0.25 & 0.35 & -28 & -28 \\
\hline $\mathrm{NO}_{\mathrm{x}}(\mathrm{ppb})$ & 0.46 & 1.2 & 38.8 & 14.9 & 37.6 & -60 & -62 & 29.0 & 45.1 & -36 & -25 \\
\hline NO (ppb) & -0.15 & -1.3 & 21.4 & 4.3 & 17.7 & -75 & -80 & 14.6 & 24.2 & -40 & -32 \\
\hline $\mathrm{NO}_{2}(\mathrm{ppb})$ & 0.61 & 3.4 & 17.4 & 10.6 & 19.9 & -47 & -39 & 14.4 & 20.9 & -31 & -17 \\
\hline $\mathrm{SO}_{2}(\mathrm{ppb})$ & 0.10 & 3.8 & 2.8 & 2.3 & 2.5 & -9 & -19 & 2.4 & 2.6 & -7 & -16 \\
\hline $\mathrm{O}_{3}(\mathrm{ppb})$ & 0.38 & 7.1 & 6.8 & 9.6 & 5.1 & 87 & 40 & 8.0 & 4.9 & 65 & 17 \\
\hline
\end{tabular}

where Period ${ }_{o b s 2020}$ corresponds to the air quality observations during the LD or the PLD, the MAM2019 ${ }_{\text {obs }}$ represents the air quality observations from March to May 2019 and Period $_{R F}$ are the RF estimates for the LD or the PLD.

Being both monitoring sites highly influenced by vehicular emissions, the reduction of $\sim 80 \%$ in traffic that was registered during the LD period led to a significant air quality improvement of primary pollutants (Figures 7 and 8). At CNEA, located in the suburbs, $\mathrm{RC}_{\mathrm{RF}}$ were $-60 \%,-47 \%$ and $-9 \%$ for $\mathrm{NO}_{\mathrm{x}}, \mathrm{CO}$ and $\mathrm{SO}_{2}$ respectively (Table 5). On the other hand, observed $\mathrm{O}_{3}$ levels were $87 \%$ and $65 \%$ higher in comparison with the estimations for the LD and PLD respectively. At PC, located in a residential-commercial area where activities during the $\mathrm{LD}$ period were more intense than in the suburbs, $\mathrm{RC}_{\mathrm{RF}} \mathrm{Were}-58 \%$ $\left(\mathrm{NO}_{\mathrm{x}}\right),-22 \%(\mathrm{CO})$ and $-36 \%\left(\mathrm{PM}_{10}\right)$. Table 5 also shows an increment of primary pollutants for the PLD period compared to the $\mathrm{LD}$, reflected in smaller relative differences. This is consistent with the increment in traffic flow.

Figures 5 and 6 allow visualizing the differences in daily concentrations between observations and RF estimates for the three considered periods (BLD, LD and PLD). For CNEA, CO and $\mathrm{NO}_{\mathrm{x}}$ observations and predictions for the BLD period showed $N M B<10 \%$. Noticeably, most of the changes were observed right from the day after lockdown. Pollutant levels were almost fully recovered by the last week of the PLD period.

In what follows, the results are presented by species, highlighting the most relevant relative changes in concentrations and their relationship with wind direction and speed, using bivariate polar plots (Figures 9 and 10). Bivariate polar plots can also be helpful to distinguish potential sources that impact the monitoring sites. 

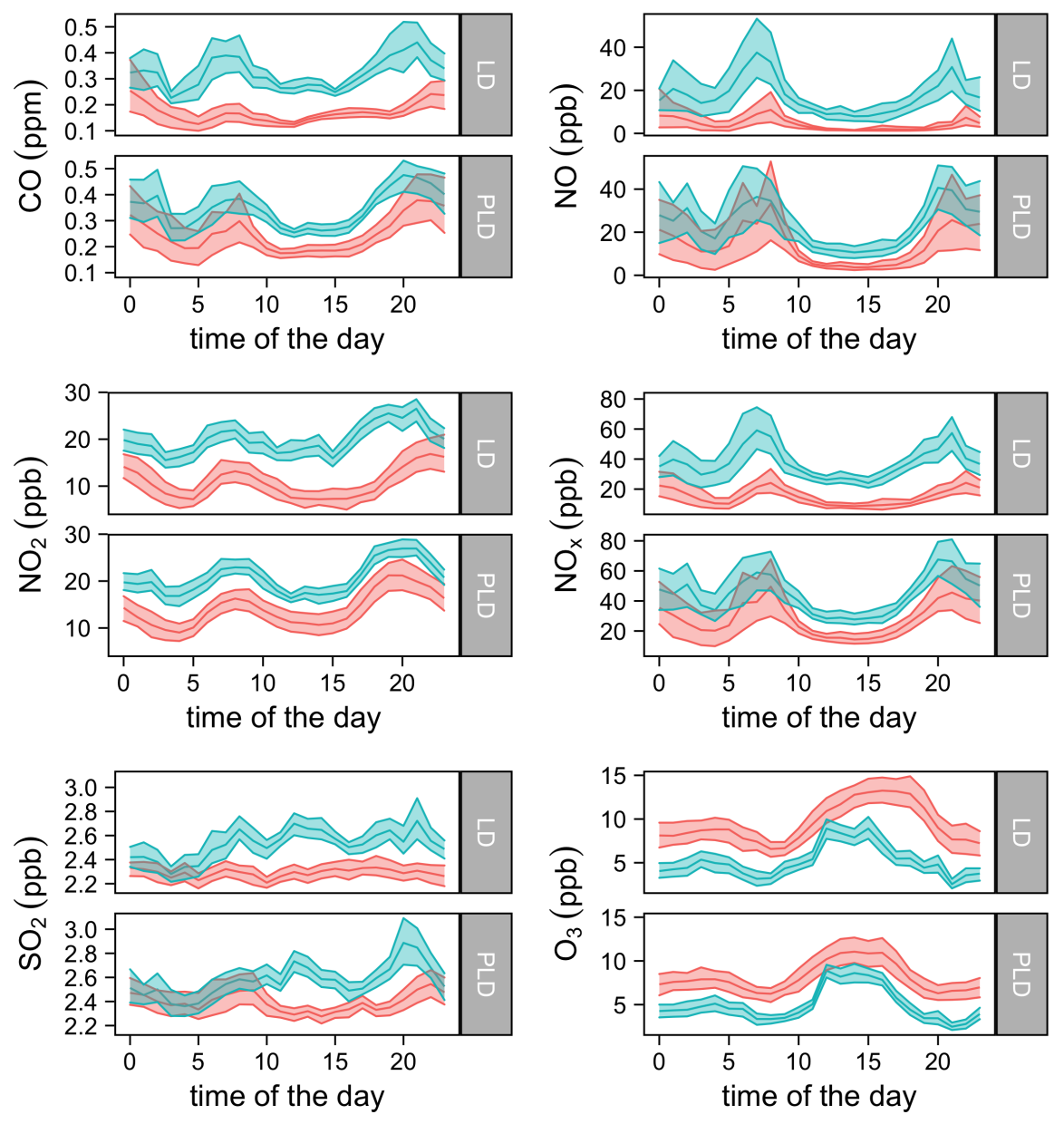

CNEA site: $\square$ Observations

BAU Scenario

Figure 7. Mean diurnal cycle for the different pollutants for the LD (from 20 March 2020 to 13 April 2020) and the PLD (13 April 2020 to 25 May 2020) for CNEA site.

\subsubsection{Carbon monoxide}

The combination of results of $\mathrm{RC}_{\mathrm{obs} 2019}$ and $\mathrm{RC}_{\mathrm{RF}}$ and the $N M B$ detected in the model for $\mathrm{CO}$ (Table 5), that is $10 \%$ for CNEA and $4 \%$ for PC, reveals the importance to assess the decrease in concentrations during COVID-19 restrictions using the $\mathrm{RF}$ model in order to consider the meteorological differences between 2019 and 2020. For PC, during the LD phase, $\mathrm{RC}_{\mathrm{obs} 2019}$ was $-28 \%$ while $\mathrm{RC}_{\mathrm{RF}}$ was $-22 \%$. Considering that the model overestimates $\mathrm{CO}$ concentrations $(N M B$ of $4 \%), \mathrm{RC}_{\mathrm{RF}}$ would be as small as $-19 \%$. Therefore, according to the $\mathrm{RF}$ model, the $\mathrm{CO}$ reductions (the opposite of $\mathrm{RC}_{\mathrm{RF}}$ ) during the $\mathrm{LD}$ period may have been of only $19 \%$ while the simple comparison between observations indicated that a larger reduction (28\%) would have occurred. Nevertheless in the PLD, estimates of relative changes were similar: $21 \%\left(\mathrm{RC}_{\mathrm{RF}}\right)$ and $17 \%\left(\mathrm{RC}_{\mathrm{obs} 2019}\right)$. For CNEA, 

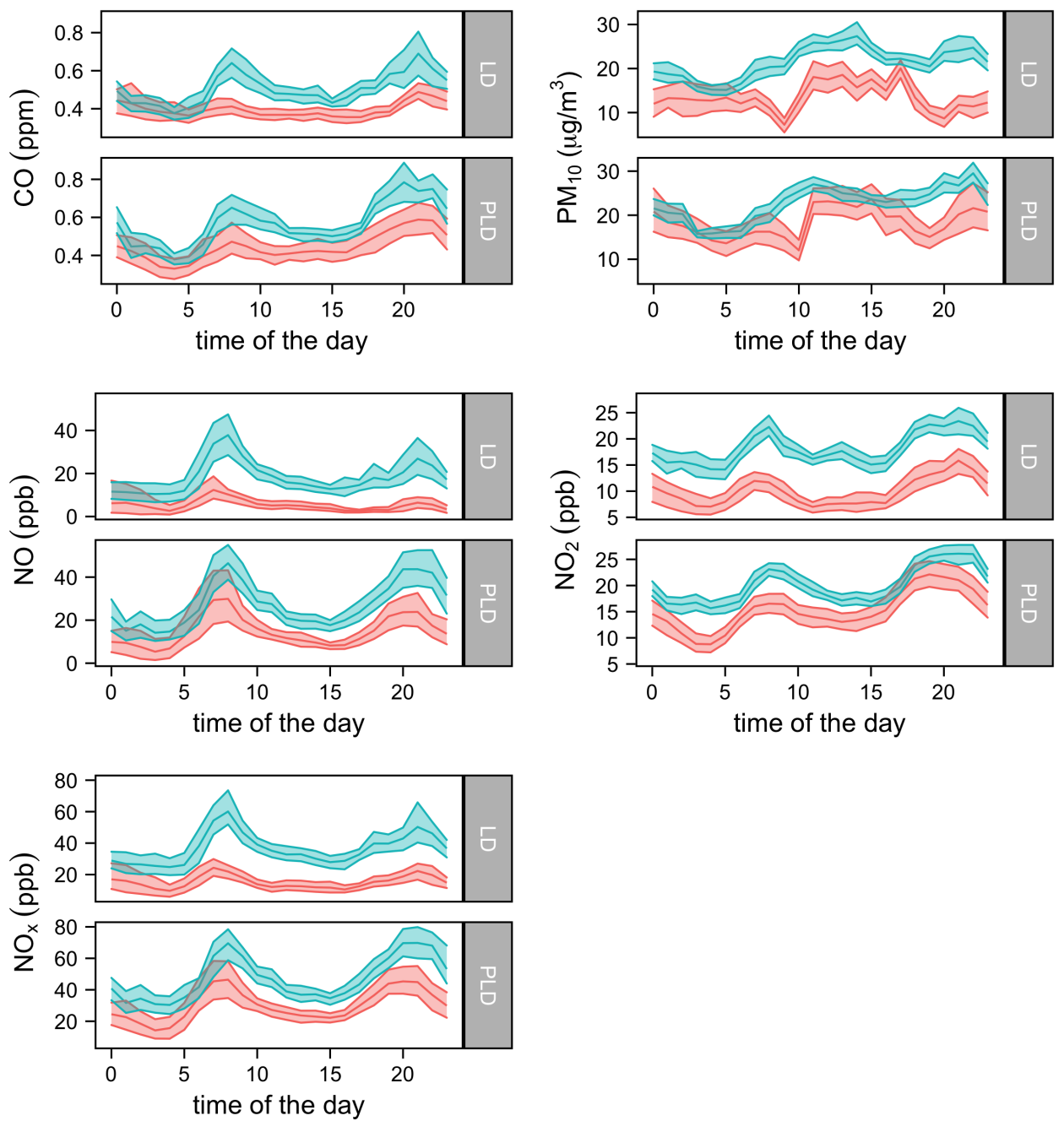

Centenario site: $\square$ Observations $\square$ BAU Scenario

Figure 8. Mean diurnal cycle for the different pollutants for lockdown (20-03-20 to 13-04-20) and partial lockdown (13-04-20 to 25-05-20) for the site PC.

during the $\mathrm{LD}$ phase, $\mathrm{RC}_{\mathrm{obs} 2019}$ was $-47 \%$ while $\mathrm{RC}_{\mathrm{RF}}$ was $-51 \%$. Taking the bias into account, differences might be as small as $-42 \%$. Instead, during the PLD, although raw numbers were the same $(28 \%)$ for both relative changes, the positive bias in $\mathrm{RF}$ estimations makes that $\mathrm{RC}_{\mathrm{RF}}$ might have been as small as $21 \%$.

As expected, in CNEA, the partial recovery of traffic during the PLD was reflected in a smaller reduction in the CO concentrations: $47 \%$ (LD) versus 28\% (PLD). However, a similar reduction was not observed in PC: $22 \%$ (LD) versus $21 \%$ (PLD). We do not have a plausible explanation for this relatively sustained CO level during the LD and the PLD. 

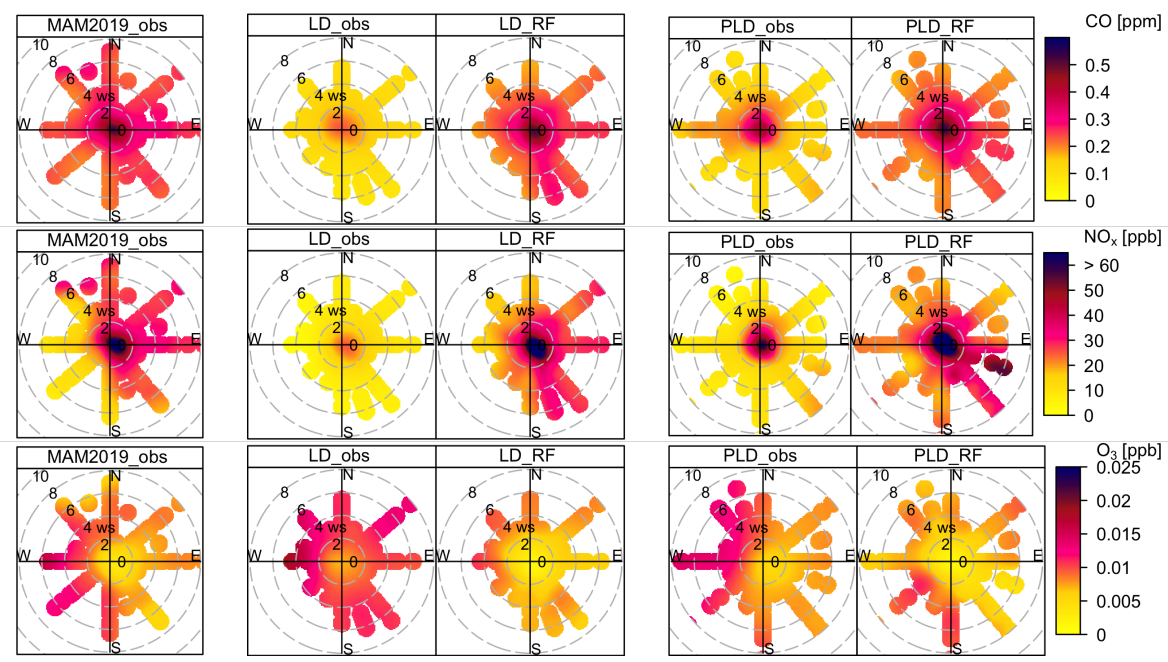

Figure 9. Bivariate polar plot for CNEA of hourly means for observations during MAM2019 and lockdown periods versus the BAU scenario estimated with RF model. The radial axis represents wind speed, the angular axis represents wind direction, and the color scale represents pollutant concentrations.
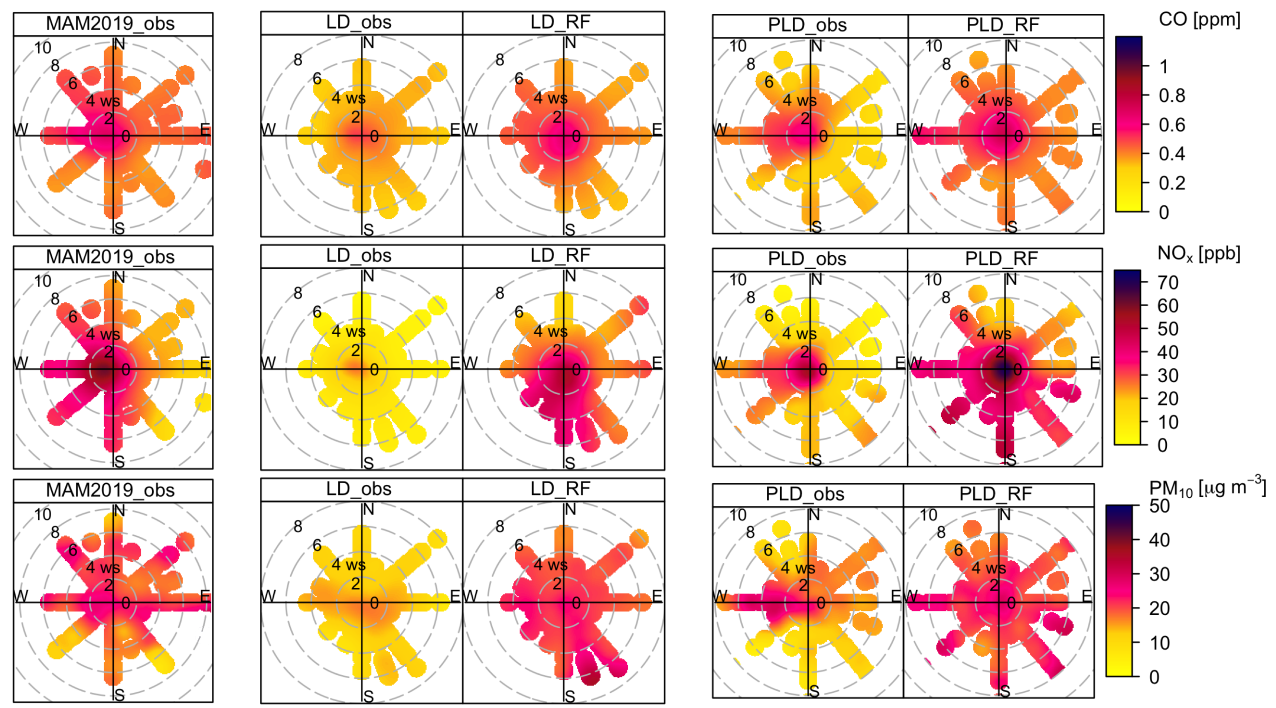

Figure 10. Bivariate polar plot for PC of hourly means for observations during MAM2019 and lockdown periods versus the BAU scenario estimated with the RF model. The radial axis represents wind speed, the angular axis represents wind direction, and the color scale represents pollutant concentrations.

Observed $\mathrm{CO}$ had lower concentration values and flatter diurnal patterns than our simulations of a BAU scenario (Figs. 7 and 8). Relative changes appeared to be significantly lower for PC than CNEA ( $-47 \%$ vs. $-22 \%$ ), but the difference in absolute 
https://doi.org/10.5194/essd-2021-318

Preprint. Discussion started: 13 October 2021

(c) Author(s) 2021. CC BY 4.0 License.

(c) (i)

terms is only $0.04 \mathrm{ppm}(0.11$ and $0.15 \mathrm{ppm}$ for PC and CNEA respectively). This is linked to a general decrease in mobile emissions, reflected in the fact that monitored hourly concentrations in CNEA were between 22\% and 62\% lower than the RF estimates. The highest differences corresponded to the morning rush hour, when RF estimates peaked while observed concentrations were largely undifferentiated from the general flat pattern. In PC, these relative decreases were in the order 36\% (morning rush hour) $>22 \%$ (afternoon) $>0.4 \%$ (night). This decrease in the CO concentrations is indicative of a decrease in traffic flow of gasoline vehicles, which are known to emit relatively higher levels of CO than diesel vehicles. This reduction far surpasses any bias detected in RF simulations, particularly during rush hours, where RF showed close to no bias (Figs. 3 and 4).

As shown in Figure 9, for the CNEA site during MAM2019, concentrations were similar for all wind directions and speeds (up to $8 \mathrm{~m} / \mathrm{s}$ ). The largest relative changes between the 2020 observations and the RF simulations were when winds were coming from the $\mathrm{E}$ and SE (both for the LD and the PLD). These were probably due to a reduction in traffic on the highway (see Section 2.4.1), which according to Diaz Resquin et al. (2018), is one of the principal sources of fuel combustion emissions.

An equivalent analysis for PC (Figure 10) yielded similar results during MAM2019, although concentrations seemed to be largest when winds were from the $\mathrm{W}$. However, relative changes during the LD and the PLD did not seem to have a clear dominant wind direction. During the PLD, sources from the W reappeared.

\subsubsection{Nitrogen oxides}

The drastic reduction of vehicular emissions impacted positively in the $\mathrm{NO}_{\mathrm{x}}$ levels. Both sites presented relative changes of around $-60 \%$ for the $\mathrm{LD}$ and an absolute difference of around $-20 \mathrm{ppb}$ for the $\mathrm{NO}_{\mathrm{x}}$ concentrations, when comparing $\mathrm{RF}$ estimations with MAM2020 obs. Considering that the $\mathrm{NO}_{\mathrm{x}}$ biases are positive, a similar analysis to that discussed for the $\mathrm{CO}$ relative changes could also be done. However, the $N M B$ of this pollutant is in the range between $1.2 \%$ and $3 \%$ and, for this reason, both relative changes remain similar. Discrepancies of $\sim 10 \%$ in the relative changes were found in the PLD period. Concentrations were consistently smaller during the day (see Figs. 7 and 8).

In both sites, the relative change of $\mathrm{NO}_{\mathrm{x}}$ was larger than that of $\mathrm{CO}$. Arguably, this indicates that the power plants did not contribute in any major way to the observed differences. This is probably due to a reduced circulation of diesel vehicles, which are the major $\mathrm{NO}_{\mathrm{x}}$ emitters (D'Angiola et al., 2010; Ghaffarpasand et al., 2020).

Fig. 9 shows the bivariate polar plots of the $\mathrm{NO}_{\mathrm{x}}$ concentrations at the CNEA site. The bivariate polar plot in MAM2019 provides evidence for two main contributing sources. One source was due to air masses from E-SE directions at low wind speeds and the second source was associated with higher wind speeds from N-NW direction. The source to the E-SE could be dominated by ground-level road traffic emissions that are closer to the site because high concentrations under low wind speeds are indicative of surface emissions released with little or no buoyancy (Uria-Tellaetxe and Carslaw, 2014). Also, the wind direction where this source was dominant corresponds to the highway previously described in Section Observational Data CNEA. The source to the N-NW was associated with high concentrations at high wind speeds, which is indicative of emissions at a greater distance. It is plausible to attribute these $\mathrm{NO}_{\mathrm{x}}$ levels to the main access avenue that connects the city with the suburbs and is located in this direction, due to the presence of heavy-duty diesel vehicles and buses and the number of flowing 
traffic stops. During the LD and the PLD, the highest $\mathrm{RC}_{\mathrm{RF}}$ were present when winds were coming from the highway. This serves as further evidence that the observed effects were mainly due to changes in traffic, and not to the changes in residential emission patterns due to lifestyle changes during the lockdown.

In the case of PC, as shown in Figure 10, during MAM2019, the main sources seemed to be located to the W and SW of the station. These two directions entailed the largest changes due to restrictions during the LD period. During the PLD period, in a similar manner than $\mathrm{CO}$, the sources to the $\mathrm{W}$ were partially restored (although concentrations from the SW remained low).

\subsubsection{Ozone}

By contrast to the other pollutants considered, the $\mathrm{O}_{3}$ increased when compared to a no-restrictions scenario. Its relative changes estimated using RF were 87\% and 65\% during the LD and the PLD periods respectively while the ones estimated through direct comparison with MAM2019 ${ }_{\mathrm{obs}}$ were $40 \%$ and 17\%. Moreover, if the positive bias is considered, the differences between $\mathrm{RC}_{\mathrm{RF}}$ and $\mathrm{RC}_{\mathrm{obs} 2019}$ could be even larger.

Recent studies of the lockdown effects on atmospheric composition have also reported large $\mathrm{O}_{3}$ increases at urban sites and indicated the need of analyzing changes in precursor emissions and meteorological parameters in light of their role in the nonlinear response in the $\mathrm{O}_{3}$ concentrations (Ordóñez et al., 2020; Tobías et al., 2020; Nakada Kondo and Urban, 2020; Shi and Brasseur, 2020). Hence, consideration of the joint effects of the changes on precursors and meteorology are of great value to understand the differences between the relative changes estimated using RF concentrations and MAM2019 ${ }_{\text {obs. }}$ Based on Figures 5 and 7, we provide plausible explanations for these discrepancies.

It is well-known that decreasing $\mathrm{NO}_{\mathrm{x}}$ levels in a VOC-limited regime tend to increase $\mathrm{O}_{3}$. It is most likely that the lower concentrations of freshly emitted NO registered during LD and PLD in CNEA provoked a decline in the local scavenging of $\mathrm{O}_{3}$, leading to higher $\mathrm{O}_{3}$ concentrations, particularly in the morning (Tobías et al., 2020; Nakada and Urban, 2020). Even though NO is the pollutant that had the highest relative decrease during the LD and the PLD, its reduction is not enough to explain the overall relative increase in $\mathrm{O}_{3}$, and therefore $\mathrm{NO}_{2}$ might have played a role as well. Lower $\mathrm{NO}_{2}$ levels could have also resulted in more $\mathrm{OH}$ to initiate $\mathrm{O}_{3}$ production because the inhibition of termination reaction favors faster $\mathrm{O}_{3}$ accumulation (Seguel et al., 2012).

With respect to the role of aerosols, it is worth noting that a significant decrease in $\mathrm{PM}_{10}$ was registered in PC. This likely implied consequent reduction not only in the mass concentrations of $\mathrm{PM}_{2.5}$ and $\mathrm{PM}_{1}$ but especially in the number concentration of fine and ultrafine particles (Arkouli et al., 2010; Gelman Constantin et al., 2021). A similar situation most likely occurred in CNEA. This could have led to greater photolysis due to the decrease in emissions of fine particles as a consequence of the vehicular restrictions imposed during the lockdowns, which in turn could have led to higher $\mathrm{O}_{3}$ concentrations (Wang et al., 2019).

Lastly, meteorological factors might be relevant. The effects of meteorology can be rather complex since the $\mathrm{O}_{3}$ precursor concentrations and reaction rates are affected in multiple ways (Wang et al., 2017). Therefore, they are not easy to analyze individually. In our simulations, although only winds and the variable daynight were included directly, temperature and relative humidity do affect $\mathrm{O}_{3}$ precursors. Solar radiation, which is highly relevant for $\mathrm{O}_{3}$ chemistry, is also linked to the variable 
daynight. In this particular case, during the $\mathrm{LD}$, elevated $\mathrm{O}_{3}$ concentrations occurred on days with high temperatures and low winds, which favor the photochemical production of $\mathrm{O}_{3}$ and the accumulation of ozone and its precursors.

As expected, the bivariate polar plots (Figure 9) show that $\mathrm{O}_{3}$ behaved opposite to $\mathrm{NO}_{\mathrm{x}}$, having the largest increases when winds came from the $\mathrm{E}$ and SE during the LD and also when they came from the E and NW during the PLD.

From these results, we can also derive that the area where the CNEA site is located behaves as a region with a VOC-limited chemical regime, because the reduction in $\mathrm{NO}_{\mathrm{x}}$ emissions caused an increase in ozone concentrations (Blanchard and Fairley, 2001; Heuss et al., 2003; Yarwood et al., 2003; Blanchard and Tanenbaum, 2006). We identified a similar behavior of increasing $\mathrm{O}_{3}$ concentrations under decreasing $\mathrm{NO}_{\mathrm{x}}$ levels when analyzing the 2019 data for weekends. This is related to the denominated weekend effect in a VOC-limited regime (Koo et al., 2012).

\subsubsection{Sulphur dioxide}

During the $\mathrm{LD}$, the $\mathrm{SO}_{2}$ seemed to be slightly lower (about 9\%) than the RF simulations and major differences between model and observations during the lockdown periods were during the afternoon and night (Figure 7). However, it should be noted that during the BLD the model overestimated $\mathrm{SO}_{2}$ during the afternoon by about $10 \%$. These values are quite different to direct comparison with MAM2019 ${ }_{\text {obs }}$, which exhibited 19\% lower concentrations during the same period. During the PLD, the $\mathrm{SO}_{2}$ concentrations were $7 \%$ and $16 \%$ lower than RF and MAM2019 ${ }_{\text {obs }}$ respectively.

A potential reason for observing smaller differences between BAU estimates and observations would be that the main source of this pollutant are the vehicle emissions of heavy-duty diesel trucks, that are mainly associated with essential activities, which were the least affected by lockdown restrictions. Therefore, further research would be needed before drawing conclusions about this pollutant.

\subsubsection{Particulate matter $10 \mu \mathrm{m}$}

During the LD phase, the RC of $\mathrm{PM}_{10}$ levels were similar: $-36 \%$ (RF) and -38\% (obs2019). Also, in this case, the negative bias, $-1.2 \%$, would make this difference even smaller. During the $\mathrm{PLD}, \mathrm{RC}_{\mathrm{RF}}$ was $-19 \%$ and $\mathrm{RC}_{\mathrm{obs} 2019},-16 \%$. $\mathrm{BLD}$ levels were recovered about eight weeks after LD's inception.

When winds are taken into account (Figure 10), we observe a general reduction from all directions during the LD. Two sources account for this: (i) the anthropogenic $\mathrm{PM}_{10}$ emissions close to the monitoring site that were mostly from vehicle diesel combustion and soot resuspension and (ii) natural sources, such as dust emissions, from the nearest large open area. In a similar fashion to $\mathrm{CO}$ and $\mathrm{NO}_{\mathrm{x}}$, sources from the $\mathrm{W}$ were reestablished during the PLD.

\subsection{Vehicle emission reduction strategies and air pollution in the MABA}

Strategies for controlling pollution from vehicular emissions in the MABA must take into account the relative reductions of $\mathrm{NO}_{\mathrm{x}}$ and VOCs to avoid an unintended increment in $\mathrm{O}_{3}$ concentrations. The atmosphere in the MABA is usually cleaned up during the night, due to a flat topography and the city's wind dynamics. Therefore, criteria pollutants rarely surpass air quality 
norms. Even though no specific policies to reduce them have been implemented, greenhouse emission policies that are in place and affect traffic may have a major impact. These include (i) technological advances in diesel buses, that should reduce $\mathrm{NO}_{\mathrm{x}}$ and $\mathrm{PM}_{10}$, without a major impact in VOCs and (ii) an increase of the fraction of electric cars, which should reduce $\mathrm{NO}_{\mathrm{x}}$ and VOC concentrations. Thus, if $\mathrm{NO}_{\mathrm{x}}$ emissions decrease like they did during the COVID lockdown, this will likely result in an important increment in tropospheric $\mathrm{O}_{3}$ in the MABA if no additional measures regarding VOCs emissions are included. In fact, under the VOC-limited regime identified for the MABA, control of VOCs emission would be more efficient to reduce local peaks in $\mathrm{O}_{3}$.

This highlights the importance of having comprehensive air quality policies rather than focusing on reductions in individual pollutants.

\section{Code and data availability}

Hourly concentrations of $\mathrm{CO}, \mathrm{NO}, \mathrm{NO}_{2}, \mathrm{SO}_{2}$ and $\mathrm{O}_{3}$ in CNEA, are available in .csv format at https://data.mendeley.com/ datasets/h9y4hb8sf8/1 (Diaz Resquin et al., 2021). We also provide an introductory R notebook with some baseline simulations. For PC regulatory averages are publicly available and can be accessed through their website (https://data.buenosaires.gob.ar/ dataset/calidad-aire). Nevertheless hourly data is not regularly reported, but can be requested to the Environmental Protection Agency of Buenos Aires City. To enable a machine learning quick start to reproduce the baseline experiments, we also added to the dataset the meteorological data used to run the simulations. It is publicly available at the website of the National Weather Service (https://www.smn.gob.ar/descarga-de-datos).

\section{Summary and conclusions}

The RF model was trained with a set of 1-year air pollutant concentrations determined in two monitoring sites of the metropolitan area of Buenos Aires. The performance of the model used in a predictive mode was tested on the basis of observations registered before the outbreak of the COVID-19 pandemic. Observations in the two first phases of the lockdown measures imposed were compared against observations in 2019 and the business-as-usual RF simulated concentrations. In addition, this study provided information on $\mathrm{O}_{3}$ and $\mathrm{SO}_{2}$ concentrations that is still scarce and fragmentary for the large urban conglomerate. The main conclusions are listed below:

(i) The resulting set of explanatory variables for the different pollutants in each site provides evidence of the need for careful identification during the training period. Although ideally the best explanatory variables could be identified by trial and error by non-experienced users of RF models, it is advisable to count with expert judgment for a meaningful and relatively fast selection;

(ii) The RF model was able to reproduce air quality observations at two monitoring stations in the MABA when it was tested for a 15-day period previous to the outbreak of the COVID-19 pandemic. This approach allowed predicting pollutant daily mean values with a mean bias of less than $11 \%$ by using data of air quality, emissions and meteorology 
and analyzing the effect of wind direction and speed in pollutant concentration, which is useful when characterizing pollution sources;

(iii) The atmospheric concentrations of $\mathrm{CO}, \mathrm{NO}_{\mathrm{x}}$ and $\mathrm{PM}_{10}$ decreased and $\mathrm{O}_{3}$ increased in comparison with the same period of the previous year and the RF estimations. In the case of $\mathrm{CO}, \mathrm{NO}_{\mathrm{x}}$ and $\mathrm{PM}_{10}$, the difference between the two methodologies was less than $11 \%$, but considering the model bias of each pollutant, these differences could be larger in all cases except for $\mathrm{PM}_{10}$ during the $\mathrm{LD}$. However, in the case of $\mathrm{O}_{3}$, which has a complex chemistry and nonlinear dependence with its precursors and with meteorology, it was larger than $40 \%$. The relative changes in pollutant concentrations attributable to lockdown are closely linked to the reduction in traffic. On one hand, this could be noted in the changes in the observed and simulated diurnal patterns. On the other hand, the effect of the circulation of vehicles could also be observed when analyzing the bivariate polar plots made possible by the use of the modelling technique. This allowed us to locate likely emission sources, mostly from high traffic directions.

(iv) The main advantage of using RF estimations instead of comparing with the same period of the previous year lies in taking into account changes in the meteorology that might influence pollutant concentrations, with only a marginal increase in the workload and computational cost. This feature of the model can be used to evaluate the effects of air pollution control policies and measures while taking into account changes in meteorology. For a successful application, it is essential to use a set of data in which emissions are similar to those that are expected to be simulated. Taking into account that the MABA has thus far only six long-term air quality monitoring stations, we believe that this methodology could be used by local authorities, both for forecasting and evaluating regulatory measures. Relations between different pollutants can also be readily included, which is of particular interest for those that have very complex chemistry, such as $\mathrm{O}_{3}$. The observational input data needed for future RF simulations can be readily updated. Most available RF models are user friendly, rather straightforward to implement and do not require large computational capacity. The methodology is amenable to be adapted to different time periods and sites and implemented by the technical staff of regulatory agencies. Expert advice may be needed during the selection of the predictive variables and model optimization;

(v) In this work we provide the first year-long in situ observational dataset on tropospheric $\mathrm{O}_{3}$ and $\mathrm{SO}_{2}$, outside of an industrial area for the MABA in the last decade. We also provide co-located concentrations of $\mathrm{CO}, \mathrm{NO}$ and $\mathrm{NO}_{2}$;

(vi) According to our measurements, the MABA seems to be in a VOC-limited regime. If VOC emissions are not carefully regulated, a $\mathrm{NO}_{\mathrm{x}}$ reduction would imply an increase in the tropospheric $\mathrm{O}_{3}$. Knowing how the concentrations of $\mathrm{O}_{3}$ in the troposphere respond to reducing the emissions of its precursors is relevant when planning appropriate strategies to reduce $\mathrm{CO}, \mathrm{NMVOCs}$ and $\mathrm{NO}_{\mathrm{x}}$ emissions. Even though this classification is limited due to the fact that we only have single point measurements, this could be a useful starting point for a more thorough characterization of the ozone regime in this urban area. 
https://doi.org/10.5194/essd-2021-318

Preprint. Discussion started: 13 October 2021

(c) Author(s) 2021. CC BY 4.0 License.

(c) (1)

Author contributions. Díaz Resquín, Melisa: Conceptualization, Methodology, Validation, Data curation, Data Analysis, Formal analysis, Writing - original draft, review \& editing. Lichtig, Pablo: Data Analysis, Formal analysis, Writing - original draft, review \& editing. Alessandrello, Diego: Data Acquisition, Data curation, Writing - original draft. De Oto, Marcelo: Data Acquisition, Writing - original draft, review \& editing. Castesana, Paula: Data Analysis, Writing - review. Rössler, Cristina: Data Analysis, Writing - original draft. Gómez, Darío: Funding acquisition, Supervision, Formal analysis, Writing - original draft, review \& editing. Dawidowski, Laura: Funding acquisition, Conceptualization, Supervision, Formal analysis, Writing - original draft, review \& editing.

Competing interests. The authors declare that no competing interests are present.

Acknowledgements. We want acknowledge the participation of the entire group of Atmospheric Chemistry of the National Atomic Energy Commission of Argentina (CNEA) to hold the campaign even during Lockdown. This study was carried out in part with the aid of grants PICT-O 2016-4802 (Agencia Nacional de Promoción Científica y Tecnológica, Argentina) and PICT 2016-3590 (Fondo para la Investigación Científica y Tecnológica). The research work that leads to the results has also been funded by the EU Horizon 2020 Marie SkłodowskaCurie project PAPILA (GA 777544, MSCA action for research and innovation staff exchange). The authors wish to thank the Environmental Protection Agency of Buenos Aires (APRA) and the National Weather Service of Argentina (SMN) for sharing air quality and meteorological data for this study. 
https://doi.org/10.5194/essd-2021-318

Preprint. Discussion started: 13 October 2021

(c) Author(s) 2021. CC BY 4.0 License.

(c) (i)

\section{References}

Act 1356: Preservación del recurso aire y prevención y control de la contaminación atmosférica., Available at https://www.buenosaires.gob. ar/sites/gcaba/files/documents/ley_1356.pdf (2021/09/07), 2004.

Aktay, A., Bavadekar, S., Cossoul, G., Davis, J., Desfontaines, D., Fabrikant, A., Gabrilovich, E., Gadepalli, K., Gipson, B., Guevara, M., Kamath, C., Kansal, M., Lange, A., Mandayam, C., Oplinger, A., Pluntke, C., Roessler, T., Schlosberg, A., Shekel, T., Vispute, S., Vu, M., Wellenius, G., Williams, B., and Wilson, R. J.: Google COVID-19 Community Mobility Reports: Anonymization Process Description (version 1.1), 2020.

Anapolsky, S.: ¿ cómo nos movemos en el AMBA? Conclusiones de la evidencia empírica y alternativas post-covid, Universidad de San Martín. ISSN: 2469-1631 Serie: Documentos de Trabajo del IT. Available at https://www.unsam.edu.ar/institutos/transporte/publicaciones/ Documento\%2018\%20Comonos\%20movemos\%20en\%20el\%20AMBA\%20-\%20Anapolsky.pdfl (2021/09/07), 2020.

Arkouli, M., Ulke, A. G., Endlicher, W., Baumbach, G., Schultz, E., Vogt, U., Müller, M., Dawidowski, L., Faggi, A., Wolf-Benning, U., and Scheffknecht, G.: Distribution and temporal behavior of particulate matter over the urban area of Buenos Aires, Atmos. Pollut. Res., 1, 1-8, https://doi.org/https://doi.org/10.5094/APR.2010.001, 2010.

Barros, V., Clarke, R., and Dias, P. S.: Climate change in the La Plata basin, Publication of the Inter-American Institute for Global Change Research (IAI), São José dos Campos, Brazil, 2006.

Blanchard, C. and Tanenbaum, S.: Weekday/Weekend differences in ambient air pollutant concentrations in atlanta and the southeastern United States., J Air Waste Manag. Assoc., 56, 271-284, https://doi.org/doi: 10.1080/10473289.2006.10464455., 2006.

Blanchard, C. L. and Fairley, D.: Spatial mapping of VOC and $\mathrm{NO}_{\mathrm{x}}$-limitation of ozone formation in central California, Atmos. Environ., 35, 3861-3873, https://doi.org/https://doi.org/10.1016/S1352-2310(01)00153-4, 2001.

Bon, D. M., Ulbrich, I. M., de Gouw, J. A., Warneke, C., Kuster, W. C., Alexander, M. L., Baker, A., Beyersdorf, A. J., Blake, D., Fall, R., Jimenez, J. L., Herndon, S. C., Huey, L. G., Knighton, W. B., Ortega, J., Springston, S., and Vargas, O.: Measurements of volatile organic compounds at a suburban ground site (T1) in Mexico City during the MILAGRO 2006 campaign: measurement comparison, emission ratios, and source attribution, Atmos. Chem. Phys., 11, 2399-2421, https://doi.org/10.5194/acp-11-2399-2011, 2011.

Borrego, C., Monteiro, A., Ferreira, J., Miranda, A. I., Costa, A. M., Carvalho, A. C., and Lopes, M.: Procedures for estimation of modelling uncertainty in air quality assessment, Environ. Int., 34, 613-620, https://doi.org/https://doi.org/10.1016/j.envint.2007.12.005, 2008.

Carslaw, D. C. and Ropkins, K.: openair - An R package for air quality data analysis, Environ. Model. Softw., 27-28, 52-61, https://doi.org/https://doi.org/10.1016/j.envsoft.2011.09.008, 2012.

Castesana, P., Diaz Resquin, M., Huneeus, N., Puliafito, E., Darras, S., Gómez, D., Granier, C., Osses Alvarado, M., Rojas, N., and Dawidowski, L.: PAPILA dataset: a regional emission inventory of reactive gases for South America based on the combination of local and global information, Earth Syst. Sci. Data Discuss., 2021, 1-34, https://doi.org/10.5194/essd-2021-208, 2021.

Cazorla, M., Herrera, E., Palomeque, E., and Saud, N.: What the COVID-19 lockdown revealed about photochemistry and ozone production in Quito, Ecuador, Atmos. Pollut. Res., https://doi.org/10.1016/j.apr.2020.08.028, 2020.

D’Angiola, A., Dawidowski, L. E., Gómez, D. R., and Osses, M.: On-road traffic emissions in a megacity, Atmos. Environ., 44, 483-493, https://doi.org/10.1016/j.atmosenv.2009.11.004, 2010.

Decree 1074/18: Available at https://www.opds.gba.gov.ar/sites/default/files/Decreto\%201074\%2018.pdf (2021/09/07), 2018.

Decree 297/2020: Available at http://servicios.infoleg.gob.ar/infolegInternet/anexos/335000-339999/335741/norma.htm (2021/09/07), 2020. 
https://doi.org/10.5194/essd-2021-318

Preprint. Discussion started: 13 October 2021

(c) Author(s) 2021. CC BY 4.0 License.

(c) (i)

Diaz Resquin, M., Santágata, D., Gallardo, L., Gómez, D., Rössler, C., and Dawidowski, L.: Local and remote black carbon sources in the Metropolitan Area of Buenos Aires, Atmos. Environ., 182, 105-114, https://doi.org/https://doi.org/10.1016/j.atmosenv.2018.03.018, 2018.

Diaz Resquin, M. C., Alessandrello, D., De Oto, M., Lichtig, P., Bajano, H., Ponso, A., Bajano, F., Dawidowski, L., and Gómez, D.: AQ-CNEA-CAC Air quality dataset (2019-2020): "A machine learning approach to address air quality changes during the COVID-19 lockdown in Buenos Aires, Argentina", v1, Mendeley Data [data set], https://doi.org/10.17632/h9y4hb8sf8.1, 2021.

Faridi, S., Yousefian, F., Janjani, H., Niazi, S., Azimi, F., Naddafi, K., and Hassanvand, M. S.: The effect of COVID-19 pandemic on human mobility and ambient air quality around the world: A systematic review, Urban Clim., 38, 100888, https://doi.org/https://doi.org/10.1016/j.uclim.2021.100888, 2021.

Feng, R., jun Zheng, H., Gao, H., ran Zhang, A., Huang, C., xi Zhang, J., Luo, K., and ren Fan, J.: Recurrent Neural Network and random forest for analysis and accurate forecast of atmospheric pollutants: A case study in Hangzhou, China, J. Clean. Prod., 231, 1005-1015, https://doi.org/10.1016/j.jclepro.2019.05.319, 2019.

515 Freitas, S. R., Longo, K. M., Alonso, M. F., Pirre, M., Marecal, V., Grell, G., Stockler, R., Mello, R. F., and Gacita, M. S.: PREP-CHEM-SRC-1.0: a preprocessor of trace gas and aerosol emission fields for regional and global atmospheric chemistry models, Geosci. Model Dev., 4, 419-433, 2011.

Gaubert, B., Bouarar, I., Doumbia, T., Liu, Y., Stavrakou, T., Deroubaix, A., Darras, S., Elguindi, N., Granier, C., Lacey, F., Müller, J. F., Shi, X., Tilmes, S., Wang, T., and Brasseur, G. P.: Global Changes in Secondary Atmospheric Pollutants During the 2020 COVID-19 Pandemic, J. Geophys. Res.: Atmospheres, 126, 1-22, https://doi.org/10.1029/2020JD034213, 2021.

Gelman Constantin, J., Londonio, A., Bajano, H., Smichowski, P., and Gómez, D.: Plasma-based technique applied to the determination of 21 elements in ten size fractions of atmospheric aerosols, Microchem. J., 160, https://doi.org/10.1016/j.microc.2020.105736, 2021.

Ghaffarpasand, O., Beddows, D. C., Ropkins, K., and Pope, F. D.: Real-world assessment of vehicle air pollutant emissions subset by vehicle type, fuel and EURO class: New findings from the recent UK EDAR field campaigns, and implications for emissions restricted zones, Sci. Total Environ., 734, 139416, https://doi.org/https://doi.org/10.1016/j.scitotenv.2020.139416, 2020.

Grange, S. K., Lee, J. D., Drysdale, W. S., Lewis, A. C., Hueglin, C., Emmenegger, L., and Carslaw, D. C.: COVID-19 lockdowns highlight a risk of increasing ozone pollution in European urban areas, Atmos. Chem. Phys., 21, 4169-4185, https://doi.org/10.5194/acp-21-4169$2021,2021$.

Heuss, J. M., Kahlbaum, D. F., and Wolff, G. T.: Weekday/Weekend Ozone Differences: What Can We Learn from Them?, J Air Waste Manag. Assoc., 53, 772-788, https://doi.org/10.1080/10473289.2003.10466227, 2003.

IGN: Mapas base de Argentina Bicontinental y Argentina Parte Continental Americana [data set], Available at https://www.ign.gob.ar/ NuestrasActividades/InformacionGeoespacial/CapasSIG (2021/09/07).

Jiang, N. and Riley, M. L.: Exploring the utility of the random forest method for forecasting ozone pollution in SYDNEY, J. Environ. Protect. Sustainable develop, 1, 245-254, 2015.

535 Koo, B., Jung, J., Pollack, A. K., Lindhjem, C., Jimenez, M., and Yarwood, G.: Impact of meteorology and anthropogenic emissions on the local and regional ozone weekend effect in Midwestern US, Atmos. Environ., 57, 13-21, https://doi.org/https://doi.org/10.1016/j.atmosenv.2012.04.043, 2012.

Kroll, J. H., Heald, C. L., Cappa, C. D., Farmer, D. K., Fry, J. L., Murphy, J. G., and Steiner, A. L.: The complex chemical effects of COVID-19 shutdowns on air quality, Nat. Chem., 12, 777-779, https://doi.org/10.1038/s41557-020-0535-z, 2020. 
https://doi.org/10.5194/essd-2021-318

Preprint. Discussion started: 13 October 2021

(c) Author(s) 2021. CC BY 4.0 License.

(c) (i)

540 Li, K., Jacob, D. J., Liao, H., Zhu, J., Shah, V., Shen, L., Bates, K. H., Zhang, Q., and Zhai, S.: A two-pollutant strategy for improving ozone and particulate air quality in China, Nat. Geosci., 12, 906-910, https://doi.org/10.1038/s41561-019-0464-x, 2019.

Liu, Y., Wang, T., Stavrakou, T., Elguindi, N., Doumbia, T., Granier, C., Bouarar, I., Gaubert, B., and Brasseur, G. P.: Diverse response of surface ozone to COVID-19 lockdown in China, Sci. Total Environ., 789, 147 739, https://doi.org/10.1016/j.scitotenv.2021.147739, 2021.

Masih, A.: Machine learning algorithms in air quality modeling, Glob. J. Environ. Sci. Manag., 5, https://doi.org/10.22034/gjesm.2019.04.0, 2019.

Muhammad, S., Long, X., and Salman, M.: COVID-19 pandemic and environmental pollution: A blessing in disguise?, Sci. Total Environ., 728, 138 820, https://doi.org/https://doi.org/10.1016/j.scitotenv.2020.138820, 2020.

Nakada, L. Y. K. and Urban, R. C.: COVID-19 pandemic: Impacts on the air quality during the partial lockdown in São Paulo state, Brazil, Sci. Total Environ., 730, https://doi.org/10.1016/j.scitotenv.2020.139087, 2020.

550 Nakada Kondo, L. Y. and Urban, R. C.: COVID-19 pandemic: Impacts on the air quality during the partial lockdown in São Paulo state, Brazil, Sci. Total Environ., 730, 139 087, https://doi.org/https://doi.org/10.1016/j.scitotenv.2020.139087, 2020.

Ordóñez, C., Garrido-Perez, J. M., and García-Herrera, R.: Early spring near-surface ozone in Europe during the COVID-19 shutdown: Meteorological effects outweigh emission changes, Sci. Total Environ., 747, 141322, https://doi.org/https://doi.org/10.1016/j.scitotenv.2020.141322, 2020.

555 Pineda Rojas, A. L., Borge, R., Mazzeo, N. A., Saurral, R. I., Matarazzo, B. N., Cordero, J. M., and Kropff, E.: High PM10 concentrations in the city of Buenos Aires and their relationship with meteorological conditions, Atmos. Environ., 241, 117773, https://doi.org/https://doi.org/10.1016/j.atmosenv.2020.117773, 2020.

Puliafito, S. E., Allende, D. G., Castesana, P. S., and Ruggeri, M. F.: High-resolution atmospheric emission inventory of the argentine energy sector . Comparison with edgar global emission database, Heliyon, p. e00489, https://doi.org/10.1016/j.heliyon.2017.e00489, 2017.

560 R Core Team: R: A Language and Environment for Statistical Computing, R Foundation for Statistical Computing, Vienna, Austria, https: //www.R-project.org/, 2019.

Rahman, M. M., Paul, K. C., Hossain, M. A., Ali, G. G. M. N., Rahman, M. S., and Thill, J.-C.: Machine Learning on the COVID-19 Pandemic, Human Mobility and Air Quality: A Review, IEEE Access, 9, 72 420-72 450, https://doi.org/10.1109/ACCESS.2021.3079121, 2021.

565 Reich, S., Magallanes, J., Dawidowski, L., Gómez, D., Grošelj, N., and Zupan, J.: An Analysis of Secondary Pollutants in Buenos Aires City, Environmental Monitoring and Assessment, 119, 441-457, https://doi.org/10.1007/s10661-005-9035-2, 2006.

Seguel, R. J., Morales S., R. G., and Leiva G., M. A.: Ozone weekend effect in Santiago, Chile, Environ. Pollut., 162, 72-79, https://doi.org/10.1016/j.envpol.2011.10.019, 2012.

Seinfeld, J. and Pandis, S.: Atmospheric Chemistry \& Physics: From Air Pollution to Climate Change, Wiley, 1998.

570 Shi, X. and Brasseur, G. P.: The Response in Air Quality to the Reduction of Chinese Economic Activities During the COVID-19 Outbreak, Geophys. Res. Lett., 47, 1-8, https://doi.org/10.1029/2020GL088070, 2020.

Šimić, I., Lovrić, M., Godec, R., Kröll, M., and Bešlić, I.: Applying machine learning methods to better understand, model and estimate mass concentrations of traffic-related pollutants at a typical street canyon, Environ. Pollut., 263, https://doi.org/10.1016/j.envpol.2020.114587, 2020 .

575 Srivastava, A.: COVID-19 and air pollution and meteorology-an intricate relationship: A review, Chemosphere, 263, 128297, https://doi.org/https://doi.org/10.1016/j.chemosphere.2020.128297, 2021. 
https://doi.org/10.5194/essd-2021-318

Preprint. Discussion started: 13 October 2021

(c) Author(s) 2021. CC BY 4.0 License.

(c) (1)

Stafoggia, M., Johansson, C., Glantz, P., Renzi, M., Shtein, A., de Hoogh, K., Kloog, I., Davoli, M., Michelozzi, P., and Bellander, T.: A random forest approach to estimate daily particulate matter, nitrogen dioxide, and ozone at fine spatial resolution in Sweden, Atmosphere, 11, https://doi.org/10.3390/atmos11030239, 2020.

Tobías, A., Carnerero, C., Reche, C., Massagué, J., Via, M., Minguillón, M. C., Alastuey, A., and Querol, X.: Changes in air quality during the lockdown in Barcelona (Spain) one month into the SARS-CoV-2 epidemic, Sci. Total Environ., 726, 138540, https://doi.org/https://doi.org/10.1016/j.scitotenv.2020.138540, 2020.

Uria-Tellaetxe, I. and Carslaw, D. C.: Conditional bivariate probability function for source identification, Environ. Model. Softw., 59, 1-9, https://doi.org/https://doi.org/10.1016/j.envsoft.2014.05.002, 2014.

585 Velders, G. J., Willers, S. M., Wesseling, J., van den Elshout, S., van der Swaluw, E., Mooibroek, D., and van Ratingen, S.: Improvements in air quality in the Netherlands during the corona lockdown based on observations and model simulations, Atmos. Environ., 247, 118 158, https://doi.org/10.1016/j.atmosenv.2020.118158, 2021.

Wang, T., Xue, L., Brimblecombe, P., Lam, Y. F., Li, L., and Zhang, L.: Ozone pollution in China: A review of concentrations, meteorological influences, chemical precursors, and effects, Sci. Total Environ., 575, 1582-1596, https://doi.org/https://doi.org/10.1016/j.scitotenv.2016.10.081, 2017.

Wang, W., Li, X., Shao, M., Hu, M., Zeng, L., Wu, Y., and Tan, T.: The impact of aerosols on photolysis frequencies and ozone production in Beijing during the 4-year period 2012-2015, Atmos. Chem. Phys., 19, 9413-9429, https://doi.org/10.5194/acp-19-9413-2019, 2019.

Yarwood, G., Stoeckenius, T. E., Heiken, J. G., and Dunker, A. M.: Modeling Weekday/Weekend Ozone Differences in the Los Angeles Region for 1997, J Air Waste Manag. Assoc., 53, 864-875, https://doi.org/10.1080/10473289.2003.10466232, 2003.

595 Yu, R., Yang, Y., Yang, L., Han, G., and Move, O. A.: RAQ-A random forest approach for predicting air quality in urban sensing systems, Sensors (Switzerland), 16, https://doi.org/10.3390/s16010086, 2016.

Zhan, Y., Luo, Y., Deng, X., Grieneisen, M. L., Zhang, M., and Di, B.: Spatiotemporal prediction of daily ambient ozone levels across China using random forest for human exposure assessment, Environ. Pollut., 233, 464-473, https://doi.org/10.1016/j.envpol.2017.10.029, 2018. 